May 2000

ANL/TD/TM00-10

ANL/ET/TM00-1

\title{
ELECTRICALLY INSULATING COATINGS FOR V-Li SELF-COOLED BLANKET IN A FUSION SYSTEM
}

by

\author{
K. Natesan, C. B. Reed, ${ }^{1}$ M. Uz, ${ }^{2}$ J. H. Park, and D. L. Smith ${ }^{1}$ \\ Energy Technology Division
}

\author{
ARGONNE NATIONAL LABORATORY \\ 9700 South Cass Avenue \\ Argonne, Illinois 60439-4838
}

${ }^{1}$ Technology Development Division

${ }^{2}$ Lafayette College, Easton, PA

Work supported by the Office of Fusion Science, U.S. Department of Energy 


\section{CONTENTS}

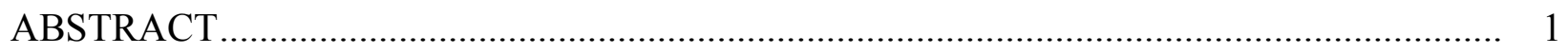

INTRODUCTION _...

Purpose of Insulator Coating ………………………............................................. 2

Evaluation of Coating Concept..................................................................................... 3

Electrical Insulation Characteristics of Candidate Coatings............................................ 4

Chemical Compatibility in Liquid Li....................................................................... 4

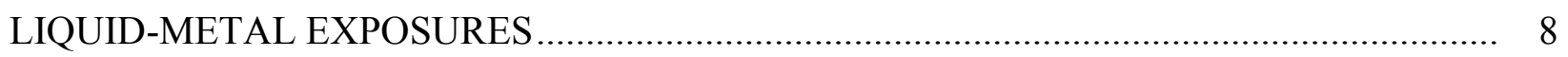

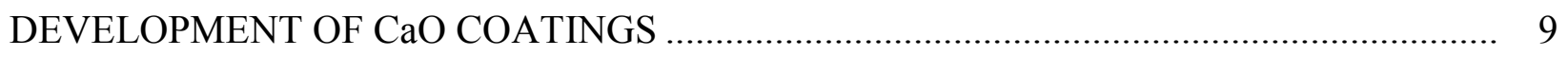

Thermal/Chemical Coating Process ........................................................................ 9

Coating Development In-Situ in Li-Ca Mixture ……….............................................. 14

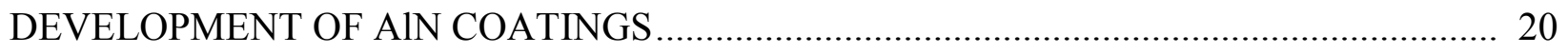

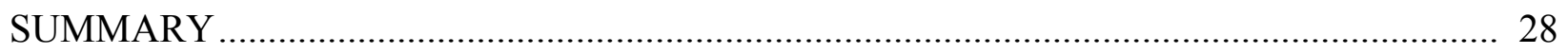

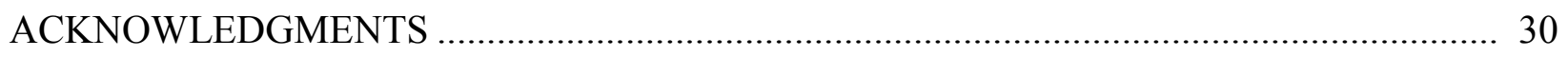

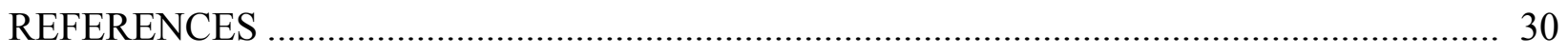




\section{FIGURES}

1. Temperature dependence of electrical resistivity of several oxides and nitrides...............5

2. Thermodynamic stability of candidate oxide coatings in Li environment ........................7

3. Thermodynamic stability of several nitrides in Li environment.......................................

4. Thermodynamic stability of AlN in Li environment containing different concentrations of $\mathrm{N}$

5. Liquid metal systems used in present study .............................................................

6. Temperature dependence of $\mathrm{Ca}$ vapor pressure ..........................................................10

7. Product of resistance times area as a function of temperature for $\mathrm{V}-4 \mathrm{Cr}-4 \mathrm{Ti}$ alloy with $\mathrm{Ca}$ deposition/oxidation and $\mathrm{Ca}$ deposition/oxidation/Ca deposition

8. Product of resistance times area as a function of time at $546^{\circ} \mathrm{C}$ for $\mathrm{V}-4 \mathrm{Cr}-4 \mathrm{Ti}$ alloy with $\mathrm{Ca}$ deposition/oxidation and $\mathrm{Ca}$ deposition/oxidation/Ca deposition

9. SEM photomicrographs of cross sections of two V-4Cr-4Ti alloy specimens after double $\mathrm{Ca}$ deposition/oxidation treatment.

10. EDX spectrum of surface of $\mathrm{V}-4 \mathrm{Cr}-4 \mathrm{Ti}$ alloy specimen after double $\mathrm{Ca}$ deposition/oxidation treatment.

11. Elemental concentrations as a function of coating thickness for $\mathrm{V}-4 \mathrm{Cr}-4 \mathrm{Ti}$ alloy specimens after double $\mathrm{Ca}$ deposition/oxidation treatment

12. Product of resistance times area as a function of temperature for $\mathrm{V}-4 \mathrm{Cr}-4 \mathrm{Ti}$ alloy with double $\mathrm{Ca}$ deposition/oxidation after 68 -h exposure in $\mathrm{Li}$ environment at $500^{\circ} \mathrm{C}$

13. Product of resistance times area as a function of time for $\mathrm{V}-4 \mathrm{Cr}-4 \mathrm{Ti}$ alloy with double $\mathrm{Ca}$ deposition/oxidation after 68 -h exposure in $\mathrm{Li}$ environment at $500^{\circ} \mathrm{C}$

14. SEM photomicrograph of surface of $\mathrm{CaO}$ coating and microcracks in coating 15

15. SEM photomicrographs of cross section and EDX depth profiles of $\mathrm{V}, \mathrm{Cr}, \mathrm{Ti}$, and $\mathrm{Ca}$ at $\mathrm{CaO} / \mathrm{V}-5 \mathrm{Cr}-5 \mathrm{Ti}$ interface of coating formed at $400^{\circ} \mathrm{C}$

16. SEM photomicrograph of surface of $\mathrm{V}-4 \mathrm{Cr}-4 \mathrm{Ti}$ alloy specimen with $\mathrm{CaO}$ coating developed in-situ in Li-Ca mixture

17. Product of resistance times area as a function of temperature for $\mathrm{V}-4 \mathrm{Cr}-4 \mathrm{Ti}$ alloy with $\mathrm{CaO}$ coating developed in-situ in $\mathrm{Li}-\mathrm{Ca}$ environment 
18. Product of resistance times area as a function of time for $\mathrm{V}-4 \mathrm{Cr}-4 \mathrm{Ti}$ alloy with $\mathrm{CaO}$ coating developed in-situ in Li-Ca environment

19. $\mathrm{Log} \mathrm{R}$ vs. time of $\mathrm{CaO}$ coating formed by exposure of $\mathrm{V}-5 \mathrm{Cr}-5 \mathrm{Ti}$ alloy to $\mathrm{Ar}$ at $650^{\circ} \mathrm{C}$ for $17 \mathrm{~h}$ and to $85 \mathrm{wt} . \% \mathrm{Ca}-\mathrm{Li}$ at $400^{\circ} \mathrm{C}$ for $17 \mathrm{~h}$

20. Temperature and product of resistance times area vs. time during thermal cycling.

21. In-situ measured product of resistance times area during Ca coating on

O-charged V-4Cr-4Ti alloy.

22. In-situ $\mathrm{R} x \mathrm{~A}$ vs. time for O-charged and previously coated $\mathrm{V}-4 \mathrm{Cr}-4 \mathrm{Ti}$ specimens in $\mathrm{Li}-2$ at. $\% \mathrm{Ca}$ at $300^{\circ} \mathrm{C}$

23. In-situ $\mathrm{R} x \mathrm{~A}$ and temperature vs. time for $\mathrm{CaO}$ coating on $\mathrm{V}-15 \mathrm{Cr}-5 \mathrm{Ti}$

24. Chemical composition from EDX analysis vs. depth for $\mathrm{CaO} / \mathrm{V}-15 \mathrm{Cr}-5 \mathrm{Ti}$ specimen after 700 -h exposure to $\mathrm{Li}-2$ at. $\% \mathrm{Ca}$ at $300-464^{\circ} \mathrm{C}$ .22

25. Pencil specimens .23

26. SEM photomicrographs of AlN-coated V-alloy specimens after hardening treatment at $900^{\circ} \mathrm{C}$ for $110 \mathrm{~h}$.

27. SEM photomicrograph in cross section of AlN-coated V-5Cr-5Ti alloy specimen after $430 \mathrm{~h}$ exposure to Li environment at $300^{\circ} \mathrm{C}$

28. EDX depth profiles for $\mathrm{Al}, \mathrm{N}, \mathrm{V}, \mathrm{Cr}$, and $\mathrm{Ti}$ for $\mathrm{V}-5 \mathrm{Cr}-5 \mathrm{Ti}$ alloy specimen after $430 \mathrm{~h}$ exposure to $\mathrm{Li}$ environment at $300^{\circ} \mathrm{C}$

29. Product of resistance times area as a function of temperature for bulk AlN after exposure in Li environment

30. Product of resistance times area as a function of time for bulk AlN after exposure in $\mathrm{Li}$ environment.

31. Product of resistance times area as a function of temperature for $\mathrm{V}-5 \mathrm{Cr}-5 \mathrm{Ti}$ alloy with AlN coating developed by PVD, after exposure in Li environment

32. Region of stability of AlN and $\mathrm{LiAlO}_{2}$ phases as a function of temperature and $\mathrm{O}$ and $\mathrm{N}$ concentrations in $\mathrm{Li}$

33. Product of resistance times area as a function of temperature for bulk $\mathrm{LiAlO}_{2}$ after exposure in $\mathrm{Li}$ environment

34. Product of resistance times area as a function of time for bulk $\mathrm{LiAlO}_{2}$ after exposure in $\mathrm{Li}$ environment 


\title{
Electrically Insulating Coatings for V-Li Self-Cooled Blanket in a Fusion System
}

\author{
by \\ K. Natesan, C. B. Reed, M. Uz, J. H. Park, and D. L. Smith
}

\begin{abstract}
The blanket system is one of the most important components in a fusion reactor because it has a major impact on both the economics and safety of fusion energy. The primary functions of the blanket in a deuterium/tritium-fueled fusion reactor are to convert the fusion energy into sensible heat and to breed tritium for the fuel cycle. The liquid-metal blanket concept requires an electrically insulating coating on the first-wall structural material to minimize the magnetohydrodynamic pressure drop that occurs during the flow of liquid metal in a magnetic field. Based on the thermodynamics of interactions between the coating and the liquid lithium on one side and the structural V-base alloy on the other side, several coating candidates are being examined to perform the insulating function over a wide range of temperatures and lithium chemistries.
\end{abstract}

\section{INTRODUCTION}

Liquid lithium is being considered as a coolant/tritium-breeding blanket for the magnetic fusion device. The structural material considered for this application is a V-base alloy with 4-5 wt.\% each of $\mathrm{Cr}$ and $\mathrm{Ti}$. In fusion applications, the structural material must be (a) compatible with the liquid metal; (b) capable of maintaining structural integrity for long periods while exposed to moderately elevated temperatures, thermal cycling, and intense irradiation; and (c) amenable to low magnetohydrodynamic (MHD) pressure losses during flow in the magnetic field.

Key performance variables of importance in application of liquid metals in firstwall/blankets include:

- Liquid-Metal Compatibility.

Corrosion due to mass transfer of metallic elements.

Mass transfer of nonmetallic elements $(\mathrm{O}, \mathrm{C}$, and $\mathrm{N})$.

Influence of corrosion on mechanical properties.

- Minimization of MHD Pressure Drop.

Candidates for electrical insulators. 
Fabrication of coatings.

Maintenance and repair of coatings.

Degradation under irradiation.

Coating effect on properties of structural materials.

- Tritium Inventory and Transport.

Hydrogen/tritium solubility in liquid metal.

Hydrogen/tritium distribution between liquid metal and structural material.

Tritium recovery methods.

Effects on structural materials.

- Safety-Related Issues.

Oxidation characteristics of structural materials.

Handling of liquid metal.

An extensive discussion on some of these issues is available in Ref. 1. The purpose of this paper is to discuss the ongoing research and development in the area of functional electrically insulating coatings for application in self-cooled liquid lithium blankets for fusion systems.

\section{Purpose of Insulator Coating}

The main challenge in the design of self-cooled blankets is accommodation of the strong influence of the magnetic field on the liquid-metal flow. If the flow direction is perpendicular to the field, a potential difference across the duct is induced in the liquid metal. This can cause a large electrical current flow if the potential difference is short-circuited by the duct walls. An electrical current flowing perpendicular to a magnetic field results in a mechanical force that leads to MHD pressure drop. ${ }^{2}$ It has been shown that even thin conducting walls would lead to a high pressure drop under the conditions of the ITER blanket; for example, the pressure drop in a poloidal duct in an inboard blanket segment would reach $8.6 \mathrm{MPa}$ if the conducting liner is 0.1 mm thick. ${ }^{3}$ This unacceptably high pressure drop shows the need for electrically insulating coatings in contact with the flowing liquid metal.

A lower limit for the pressure drop would be achieved with perfectly insulated walls. In this case, the pressure drop $(\Delta p)$ can be described by

$$
\Delta p=v \cdot B \cdot L \cdot \sqrt{\sigma \cdot \eta} / a
$$

where

$v=$ liquid metal velocity,

$\mathrm{B}=$ magnetic field strength,

$\sigma=$ electrical conductivity of the liquid metal, 


$$
\begin{aligned}
& \eta=\text { viscosity of the liquid metal, and } \\
& a=\text { duct dimension. }
\end{aligned}
$$

Substituting the dimensionless Hartmann number (M),

$$
\mathrm{M}=B \cdot a \cdot \sqrt{\sigma / \eta}
$$

leads to

$$
\Delta p=\frac{\sigma \cdot v \cdot B^{2} \cdot L}{M}
$$

and the dimensionless pressure gradient

$$
\frac{\partial p}{\partial x}=-\frac{\Delta p / L}{\sigma \cdot v \cdot B^{2}}=-\frac{1}{M}
$$

With values of $v=4 \mathrm{~m} / \mathrm{s}, a=0.1 \mathrm{~m}, \mathrm{~L}=12 \mathrm{~m}, \mathrm{~B}=12 \mathrm{~T}$, and lithium properties of $\sigma=3.3 \times 10^{6}$ $\mathrm{S} / \mathrm{m}$ and $\eta=4.5 \times 10^{-4} \mathrm{~Pa} \cdot \mathrm{s}$, the values of $\mathrm{M}$ and $\Delta p$ become $10^{5}$ and $0.22 \mathrm{MPa}$. The calculation shows that a perfectly insulating coating on the wall would decrease the pressure drop from 8.6 to $0.22 \mathrm{MPa} .^{2,3}$

Even though a very low pressure drop can be achieved with a perfectly insulating coating, in practice it is necessary to know the effect of coating integrity on the insulating characteristics because any and all of the coating methods can yield only coatings with defects such as pinholes, cracks, minute flaws, etc. Further, a pressure drop of 1-2 MPa is acceptable for a liquid-metal blanket in a fusion reactor application. Malang and Bühler ${ }^{3}$ calculated leakage currents through imperfections in the coatings and concluded that to obtain an acceptable pressure drop (1-2 $\mathrm{MPa})$ for the fusion blanket, the product of coating resistivity and coating layer thickness should have a minimum value of $100 \Omega \cdot \mathrm{cm}^{2}$.

\section{Evaluation of Coating Concept}

To evaluate the coating concept, tests were conducted at Argonne National Laboratory to evaluate the MHD performance of electrical insulator coatings that use a eutectic liquid metal of composition Na-78 wt.\% K (NaK). ${ }^{4}$ Aluminum oxide was chosen as the candidate insulating material for the proof-of-concept because it is thermodynamically stable in NaK (especially below $100^{\circ} \mathrm{C}$ ) and because of the availability of Argonne's Liquid Metal Experiment (ALEX) facility, which contains $\mathrm{NaK}$ as the working fluid. The inside pipe diameter was $10.8 \mathrm{~cm}$, the wall thickness was $2.9 \mathrm{~mm}$, the length of the uniform magnetic field was $\square 1.8 \mathrm{~m}$, and the maximum magnetic field strength was $2.0 \mathrm{~T}$.

A round pipe of type 304 stainless steel was aluminized on its inside surface by a packdiffusion method, in which the substrate material is contacted and heated for $4-12 \mathrm{~h}$ at $\square 900^{\circ} \mathrm{C}$ with a pack of powders. The composition of such powders (e.g., 65 wt.\% $\mathrm{Al}_{2} \mathrm{O}_{3}, 33$ wt.\% Al, 
2 wt.\% $\mathrm{NH}_{4} \mathrm{Cl}$ ) provides metallic $\mathrm{Al}$, alumina as filler material, and $\mathrm{NH}_{4} \mathrm{Cl}$ as activator. The $\mathrm{Al}$ deposited on the substrate surface diffuses into the subsurface regions of the material, where it forms intermetallic phases as aluminides of $\mathrm{Fe}$ and/or Ni. Because the substrate materials are heated to temperatures close to the annealing range for times sufficient to cause solution processes in the matrix, they generally need a final treatment to optimize the structure. The aluminide layers reached thicknesses of $0.025-0.20 \mathrm{~mm}$, depending on the exposure time and temperature and composition of the substrate material. The aluminum concentration reached $50 \mathrm{wt} . \%$ or more over a depth of $\square 160 \mu \mathrm{m}$ from the surface, beyond which it decreased to zero at a depth of $\square 440 \mu \mathrm{m}$.

After aluminizing by the above procedure, the pipe require oxidizing at elevated temperature for a time sufficient to develop an adherent alumina layer with adequate insulating properties. Based on the laboratory tests on oxidation of aluminized specimens, an oxidation period of $4 \mathrm{~h}$ at $982^{\circ} \mathrm{C}$ was selected for oxidation of the aluminized pipe. The alumina-coated 304 stainless steel pipe was used as a test section in MHD pressure-drop tests conducted over a 0-2 T range of magnetic field strength and an average NaK velocity of $\square 6.5 \mathrm{~cm} / \mathrm{s}$ at bulk fluid temperatures of 30 and $85^{\circ} \mathrm{C}$. The overall pressure drop across the entire magnet was determined by measuring the differential pressure between pressure taps located at each end of the test section. Test results showed that the pressure drop with an insulator coating was 25 times smaller than that obtained on an uncoated tube under identical test conditions. The measured values for the insulated pipe were somewhat higher than those calculated for a perfectly insulated pipe, and possible causes for this difference are discussed elsewhere. ${ }^{4}$

\section{Electrical Insulation Characteristics of Candidate Coatings}

A review of available information on the electrical resistivity values for several oxides, nitrides, and mixed oxides showed that oxides such as $\mathrm{CaO}, \mathrm{MgO}, \mathrm{BeO}, \mathrm{Y}_{2} \mathrm{O}_{3}$, and $\mathrm{MgAl}_{2} \mathrm{O}_{4}$, and nitrides such as $\mathrm{BN}, \mathrm{AlN}$, and $\mathrm{Si}_{3} \mathrm{~N}_{4}$ exhibit resistivities of $>10^{6} \Omega \cdot \mathrm{cm}$ at temperatures below $\square 700^{\circ} \mathrm{C}$ (see Fig. 1). The requirement is that the product of the electrical resistivity of the insulator coating and the thickness of the coating should exceed a nominal value of $100 \Omega \cdot \mathrm{cm}^{2}$ under operating conditions. This translates to a minimum resistivity value of $10^{6} \Omega \cdot \mathrm{cm}$ for a coating thickness of $1 \mu \mathrm{m}$, or $10^{5} \Omega \cdot \mathrm{cm}$ for a coating thickness of $10 \mu \mathrm{m}$. Based on the resistivity values of materials listed above, a coating layer of $<1 \mu \mathrm{m}$ in thickness of any of these materials would be adequate from the insulating standpoint, provided that resistivity is not reduced during operation, e.g., by irradiation.

\section{Chemical Compatibility in Liquid Li}

Extensive thermodynamic calculations have been performed to evaluate potential electrical insulator candidates that are chemically compatible in liquid Li for use as a coating on first-wall and blanket structural material. The issues of compatibility between the liquid $\mathrm{Li}$ and the coating 


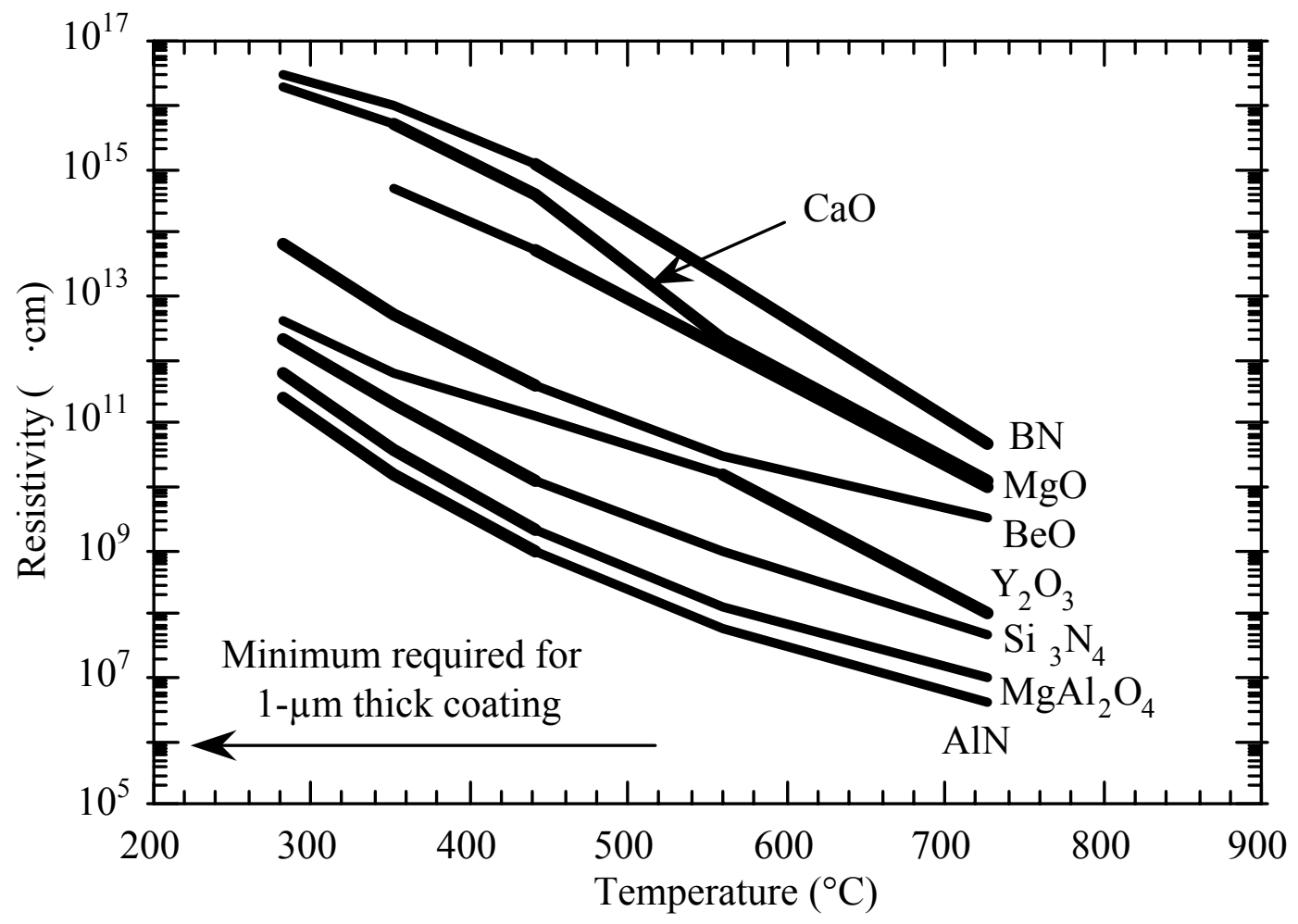

Fig. 1. Temperature dependence of electrical resistivity of several oxides and nitrides.

involve the (a) thermodynamic stability of the coating when contacted with the liquid Li; (b) extent of dissolution of the coating in the liquid $\mathrm{Li}$, which is dictated by the solubilities of coating constituents (and structural material constituents, if uncoated material or bimetallic systems are used) in liquid $\mathrm{Li}$ at temperatures and temperature gradients within the system; and (c) degrees of interaction between the coating constituents and the reactants such as $\mathrm{O}, \mathrm{C}, \mathrm{N}$, and $\mathrm{H}$ in liquid $\mathrm{Li}$, which can result in changes in chemistry of the coating, thereby altering the insulating characteristics.

\section{Transfer of Metallic Elements}

For the advanced blanket in a fusion reactor, the $\mathrm{V}-(4-5) \mathrm{Cr}-(4-5) \mathrm{Ti}$ alloy is considered the candidate structural material for first wall/blanket application. The peak temperature for the liquid metal in an advanced blanket will be $600-700^{\circ} \mathrm{C}$, with a maximum temperature gradient of $\square 100-200^{\circ} \mathrm{C}$ around the loop. Under these conditions, the mass transfer of metallic elements between the structural materials and the liquid metal is determined primarily by the leaching kinetics of the alloy constituents, which are dictated by the solubility of the constituents in the liquid metal and the temperature dependence of the solubility values. In some instances, the substrate constituents can react with nonmetallic elements such as $\mathrm{O}, \mathrm{C}$, and $\mathrm{N}$ to form stable compounds that can alter the corrosion degradation of the materials. 


\section{Transfer of Nonmetallic Elements}

Nonmetallic elements such as $\mathrm{O}, \mathrm{C}, \mathrm{N}$, and $\mathrm{H}$ are known to migrate in structuralmaterial/liquid-metal systems as a result of differences in chemical activity. A detailed analysis has been published earlier ${ }^{5-7}$ on the thermodynamics of nonmetallic impurity elements in $\mathrm{Li}$, with emphasis on purification of the liquid metals and chemical compatibility of candidate structural materials. Because the objective of this research effort is to examine the viability of coatings as electrical insulator, the rest of the paper will emphasize the thermodynamic stability of the coating candidates in $\mathrm{Li}$, the physical and chemical characteristics of the coatings, the viability of different coating methods, and the electrical insulation characteristics of the coatings.

A majority of oxides that form from the constituents (e.g., V, Cr, Ti, Si, Al, etc.) of structural materials are unstable in an $\mathrm{Li}$ environment. The distribution coefficient for $\mathrm{O}$ between these metals and $\mathrm{Li}$ is such that $\mathrm{O}$ will transfer from the metals into $\mathrm{Li}$ and that $\mathrm{O}$ concentration in $\mathrm{Li}$ has no consequence in the corrosion performance of these metals and their alloys. Therefore, from the standpoint of stable oxides in an Li environment, very few candidates are feasible. Figure 2 shows the thermodynamic stability of several oxides $(\mathrm{CaO}$, $\left.\mathrm{MgO}, \mathrm{Y}_{2} \mathrm{O}_{3}, \mathrm{BeO}\right)$ that are possible candidates for insulator application in an Li environment. It is evident that all four oxides are stable in O-saturated $\mathrm{Li}$ at temperatures of $>200^{\circ} \mathrm{C}$. Also shown in the figure are free energy values for Li that contains various concentrations $(1000,300$, 100 , and $38 \mathrm{wppm}$ ) of $\mathrm{O}$. The lowest value of 38 wppm $\mathrm{O}$ corresponds to an $\mathrm{O}$ concentration that is established by cold-trapping $\mathrm{Li}$ at $200^{\circ} \mathrm{C}$. Under these conditions, only $\mathrm{BeO}$ and $\mathrm{CaO}$ are thermodynamically stable over the wide temperature range $\left(200-700^{\circ} \mathrm{C}\right)$ of interest for fusion systems, but $\mathrm{MgO}$ and $\mathrm{Y}_{2} \mathrm{O}_{3}$ will be reduced to metal by $\mathrm{Li}$ at temperatures $>460^{\circ} \mathrm{C}$. Furthermore, based on the binary Li-Ca phase diagram, a significant amount of $\mathrm{Ca}$ can be dissolved in Li at fairly low temperatures, and this feature may aid in development of in-situ $\mathrm{CaO}$ coatings and also enable self-healing for the defects, if any, in the coatings by transport of $\mathrm{Ca}$ to the defect region and subsequent oxidation. Based on this analysis, $\mathrm{CaO}$ was selected as an insulator candidate for evaluation in $\mathrm{Li}$ systems.

Figure 3 depicts the thermodynamic stability of nitrides of several structural metals with respect to $\mathrm{N}$ concentration in an $\mathrm{Li}$ environment. The data indicate that compounds such as $\mathrm{BN}$ and AlN, which possess high resistivity, will be stable over a wide temperature range in an $\mathrm{Li}$ environment even with $\mathrm{N}$ concentrations as low as 100 wppm. $\mathrm{Si}_{3} \mathrm{~N}_{4}$ is marginally stable in $\mathrm{Li}$, while TiN, even though stable, has low resistivity. Figure 4 shows a detailed view of AlN stability relative to $\mathrm{Li}_{3} \mathrm{~N}$ and Li containing various levels of $\mathrm{N}$. Furthermore, Li has a fairly high solubility for $\mathrm{Al}$ and $\mathrm{N}$, and this feature (similar to that for $\mathrm{Ca}$ ) can enable self-healing of defects by providing flexibility in the control and maintenance of chemistry of Li. Among the nitrides, AlN was selected as a possible coating for V-Li blanket applications. 


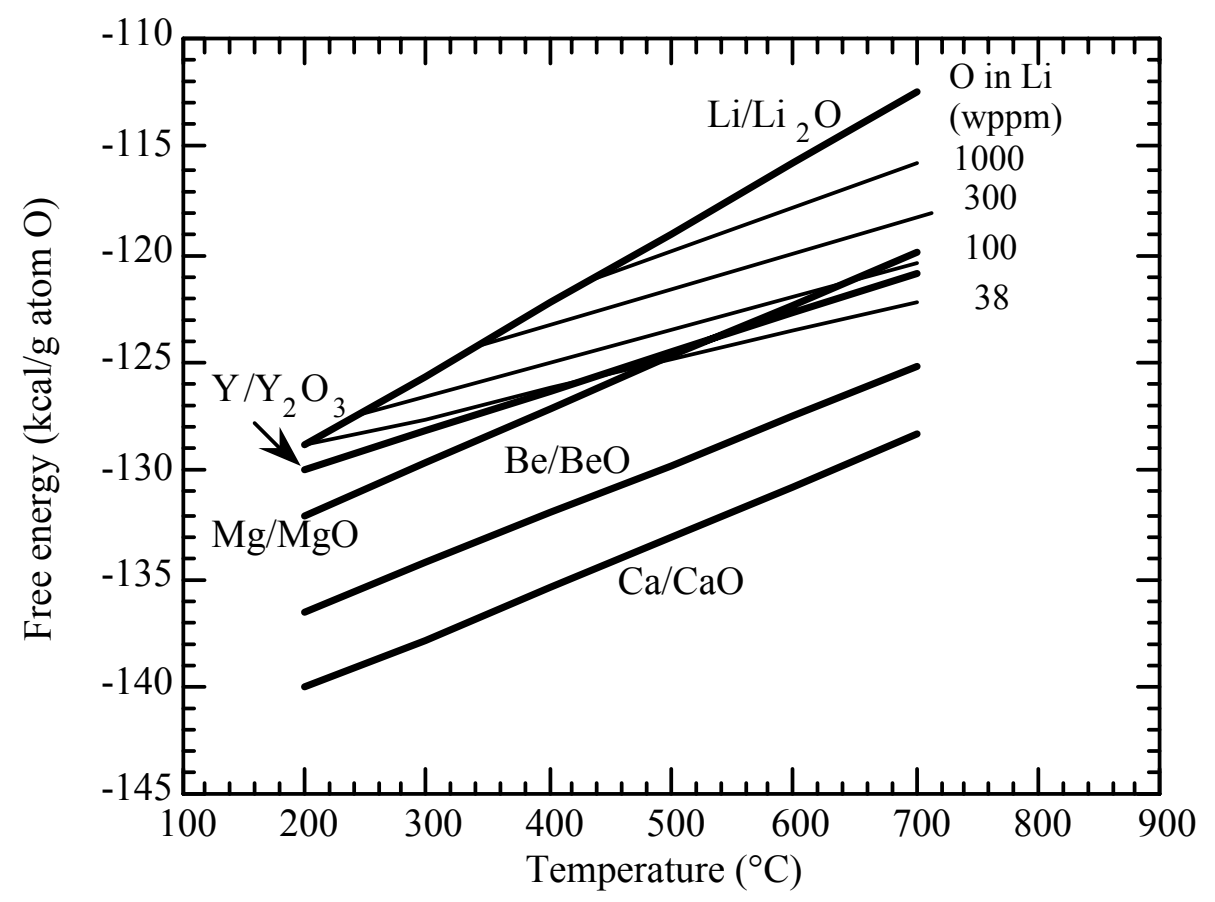

Fig. 2. Thermodynamic stability of candidate oxide coatings in Li environment.

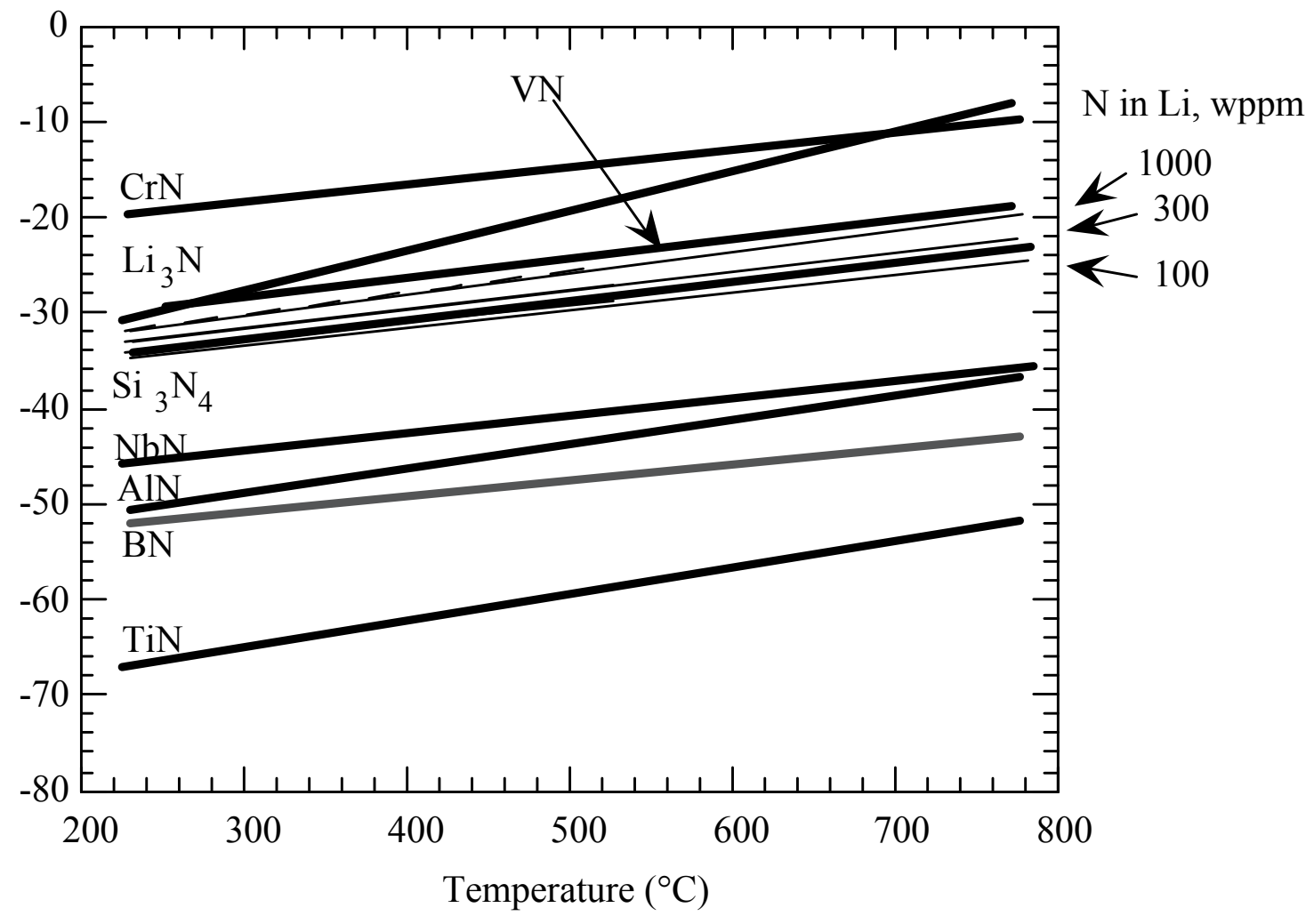

Fig. 3. Thermodynamic stability of several nitrides in Li environment. 


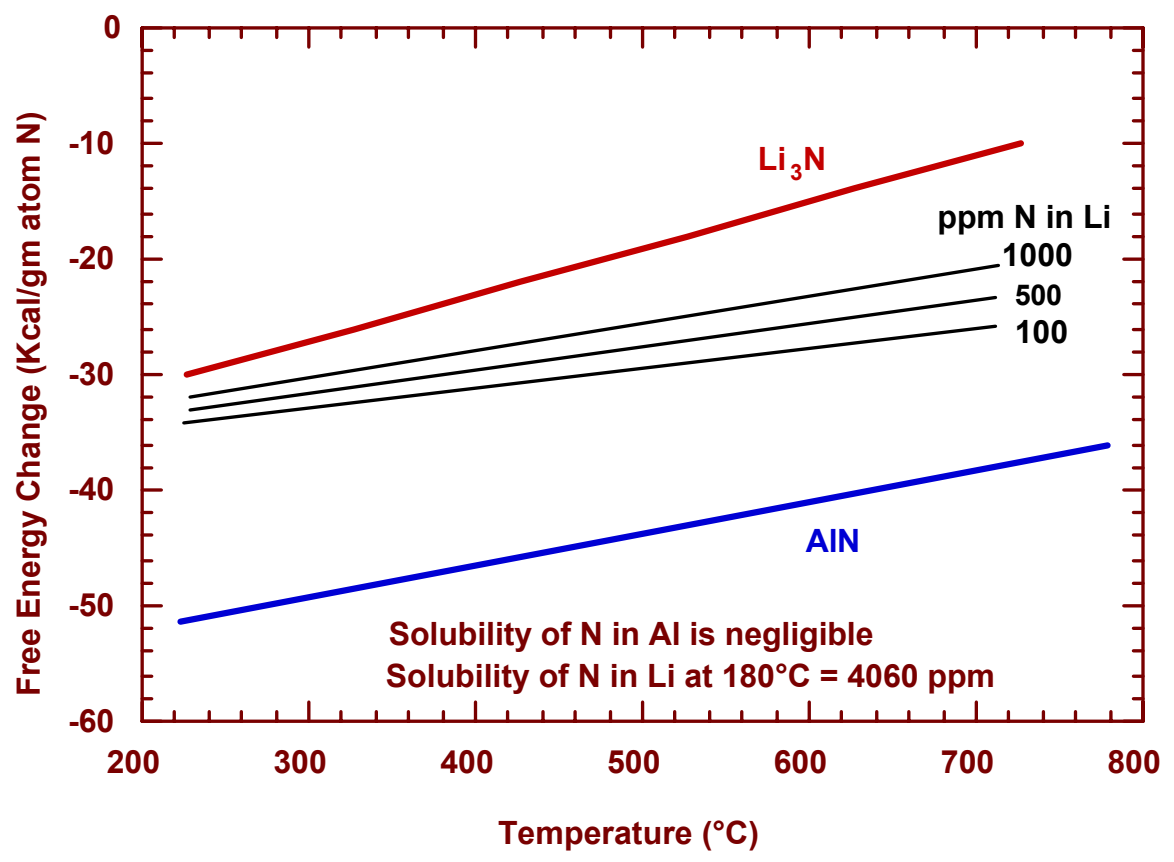

Fig. 4. Thermodynamic stability of AIN in Li environment containing different concentrations of $\mathrm{N}$.

To determine the distribution coefficients and the initial concentrations of nonmetallic elements in the solid and the liquid, one can assess the tendency for nonmetallic elements to transfer, i.e., from solid to liquid or liquid to solid. One can then evaluate the types of nonmetallic element interactions that are likely to occur and their consequences for material behavior. For stability of AIN in an Li environment, the $\mathrm{N}$ concentration in Li will be dictated by the $\mathrm{Al}$ concentration in $\mathrm{Li}$ because both $\mathrm{N}$ and $\mathrm{Al}$ have fairly high solubilities in Li. Calculations using the free-energy value for the reaction

$$
\mathrm{AlN}(\text { solid })=\mathrm{Al}(\text { in Li) }+\mathrm{N}(\text { in } \mathrm{Li})
$$

showed that the product of activities of $\mathrm{N}$ and $\mathrm{Al}$ in Li required to maintain a stable AlN phase is very low, indicating that dissolution of AlN compound will be small (even though the driving force for dissolution of either $\mathrm{N}$ or $\mathrm{Al}$ alone is large based on their solubility values in $\mathrm{Li}$ ).

\section{LIQUID-METAL EXPOSURES}

Two static liquid-Li systems were used for studies on compatibility of insulator coatings. The systems were filled with $\square 15$ L of high-purity Li (99.97 wt.\%; see Fig. 5). Concentrations of trace impurities of $\mathrm{Na}, \mathrm{Ca}, \mathrm{K}, \mathrm{Fe}, \mathrm{Si}$, and $\mathrm{Cl}$ in $\mathrm{Li}$ was $<50 \mathrm{ppm}$, and $\mathrm{N}$ concentration in the $\mathrm{Li}$ was $80 \mathrm{ppm}$. Coupon specimens of $\mathrm{CaO}$-coated samples were exposed in the liquid $\mathrm{Li}$ at $500^{\circ} \mathrm{C}$. 


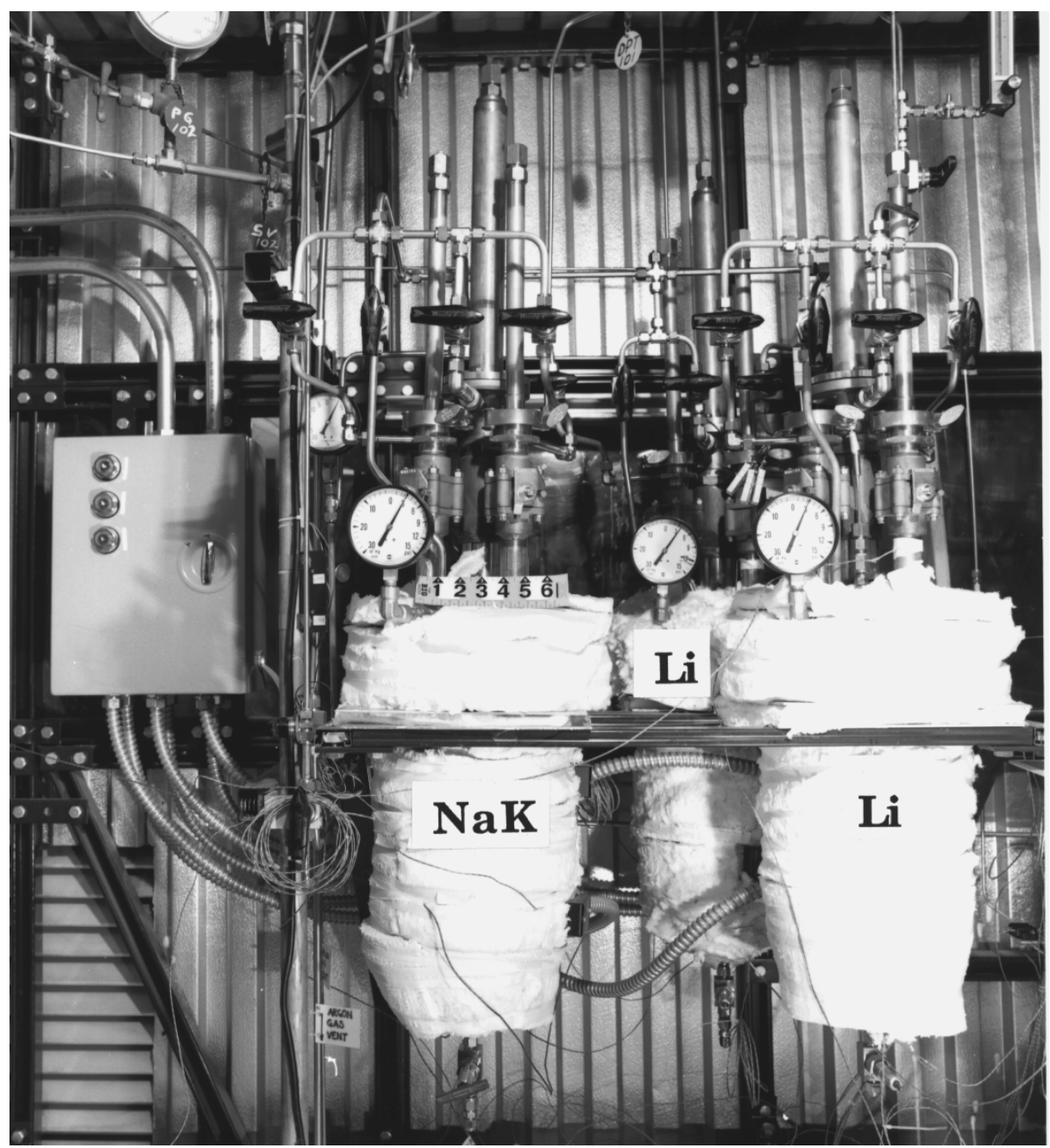

Fig. 5. Liquid metal systems used in present study.

Weight change was measured to establish the corrosion rates for the coatings as a function of time. After exposure, the specimens were examined by a scanning electron microscope (SEM) equipped with an energy-dispersive X-ray (EDX) analyzer, and also by X-ray diffraction. The coated specimens were examined to evaluate coating integrity after liquid-metal exposure, microstructural changes in coatings, coating/substrate interactions, and electrical insulation characteristics of the coatings.

\section{DEVELOPMENT OF CaO COATINGS}

\section{Thermal/Chemical Coating Process}

$\mathrm{CaO}$ coatings were developed by a vapor phase transport process external to $\mathrm{Li}$ at elevated temperature. ${ }^{8-10}$ The procedure for the thermal/chemical coating process involved exposure of $\mathrm{V}$-alloy specimens to a pack of fine $\mathrm{Ca}$ pellets at $700-800^{\circ} \mathrm{C}$. The specimens were either 
completely enclosed within the pack or hung above the pack material in a static Ar environment. Figure 6 shows the temperature dependence of the vapor pressure of $\mathrm{Ca}$. Above $700^{\circ} \mathrm{C}$, the vapor pressure of $\mathrm{Ca}$ is $>0.1$ torr and is sufficient to deposit a layer of $\mathrm{Ca}$ on the specimens. Several geometrical arrangements were examined to obtain a uniform coating of $\mathrm{Ca}$ on the specimens, which were typically coupons that measured 5 to $10 \times 5 \times 1 \mathrm{~mm}$. The exposure time in the deposition process ranged from 100 to $200 \mathrm{~h}$. Upon deposition of $\mathrm{Ca}$, the specimens were oxidized in an Ar environment to oxidize the $\mathrm{Ca}$ deposit. The oxidized specimens exhibited poor adherence of the oxide to the substrate and the oxide layer was patchy and fairly thin. A twoprobe method was used to measure the electrical resistance of these specimens by deposition of gold film over areas of $2 \times 2 \mathrm{~mm}$ and use of Pt wire for electrical leads. The specimen assembly was inserted in a furnace and resistance measurements were made in an Ar environment between room temperature and $\square 700^{\circ} \mathrm{C}$.

The coated specimens exhibited insulating characteristics after this oxidation step. X-ray diffraction studies on these specimens showed good correlation between high resistance values at room temperature and a high concentration of $\mathrm{Ca}$ in oxide form. Calcium concentrations of 60$80 \mathrm{wt} . \%$ were obtained in several specimens. However, coating thickness in a given specimen or among various specimens was not uniform; in some specimens, coating spallation was noted. The variation in the product of resistance times area as a function of temperature obtained on specimens of $\mathrm{V}-4 \mathrm{Cr}-4 \mathrm{Ti}$ alloy with $\mathrm{Ca}$ deposition/oxidation and with $\mathrm{Ca}$ deposition/oxidation and redeposition of $\mathrm{Ca}$ is shown in Fig. 7. The specimen with single-step deposition of $\mathrm{Ca}$ and oxidation exhibited (see Fig. 7a) a low value of $\square 10 \square \cdot \mathrm{cm}^{2}$ at room temperature. Upon heating the specimen during the resistance measurement, the value decreased further to as low as 0.5 $\square \cdot \mathrm{cm}^{2}$ at $546^{\circ} \mathrm{C}$. The specimen was maintained at $546^{\circ} \mathrm{C}$ overnight and the resistance gradually increased to a value of $10 \square \cdot \mathrm{cm}^{2}$; it was then given a second cycle of heating and cooling, as shown in the figure. The resistance during the second heating remained the same as it was during the cooling part of the first cycle. However, a further increase in resistance was observed during the cooling part of the second cycle. The product of the resistance times area remained in the range of $15-20 \square \cdot \mathrm{cm}^{2}$ in a temperature range of $200-500^{\circ} \mathrm{C}$.

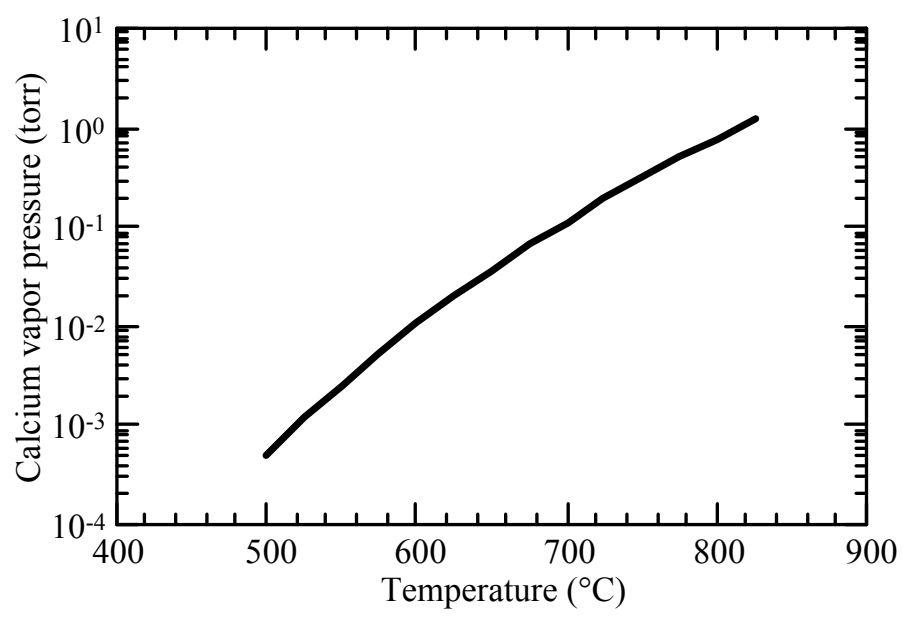

Fig. 6. Temperature dependence of $\mathrm{Ca}$ vapor pressure. 

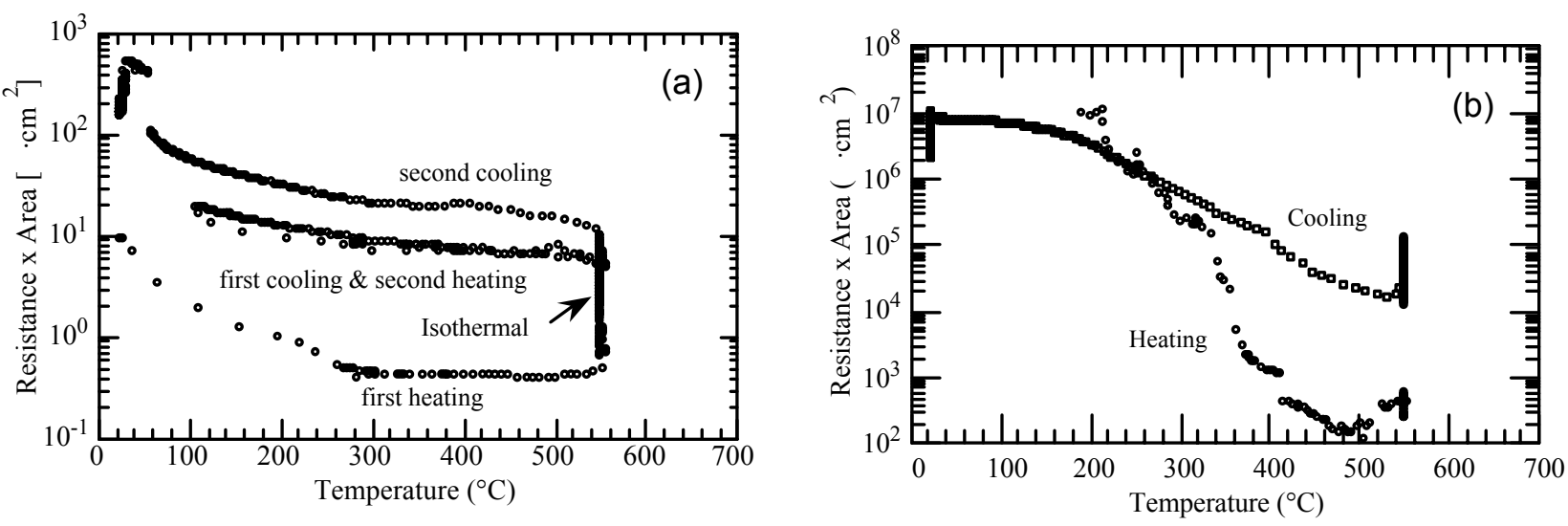

Fig. 7. Product of resistance times area as a function of temperature for $\mathrm{V}-4 \mathrm{Cr}-4 \mathrm{Ti}$ alloy with (a) Ca deposition/oxidation and (b) $\mathrm{Ca}$ deposition/oxidation/Ca deposition.

Figure $7 \mathrm{~b}$ shows the variation in values for resistance times area for a specimen treated with $\mathrm{Ca}$ deposition/oxidation/redeposition of $\mathrm{Ca}$. During the heating cycle, the value ranged from $10^{7}$ to $10^{2} \square \cdot \mathrm{cm}^{2}$ as the temperature increased from room temperature to $\square 500^{\circ} \mathrm{C}$; a sharp drop was observed within the temperature range of $200-500^{\circ} \mathrm{C}$. The specimen was maintained overnight at $546^{\circ} \mathrm{C}$ in air, during which time the value for resistance times area increased from $\square 400$ to $2 \times 10^{5} \square \cdot \mathrm{cm}^{2}$. Upon cooling, the value showed a further increase to $\square 10^{7} \square \cdot \mathrm{cm}^{2}$ at room temperature. It is evident that the dual treatment of $\mathrm{Ca}$ deposition improved the coating from the standpoints of both thickness and resistance.

The behavior of the coatings of the above two specimens at $546^{\circ} \mathrm{C}$ as a function of exposure time is shown in Fig. 8. At temperature, with a single Ca deposition treatment, the specimen exhibited a gradual increase in resistance to $5 \square \cdot \mathrm{cm}^{2}$, while the specimen with a double $\mathrm{Ca}$ treatment exhibited values of $10^{4}$ to $10^{5} \square \cdot \mathrm{cm}^{2}$. The results also showed that $\mathrm{Ca}$ deposition via vapor phase transport is possible, but that coating thickness and adhesive bonding of the coating to the substrate after a single deposition/oxidation procedure was not adequate to produce the desired insulating characteristics. Additional experiments, with several procedural modifications, were conducted and, finally, a double deposition/oxidation treatment seemed to produce a thicker coating that was more adherent and exhibited adequate insulating characteristics at room temperature.

Figure 9 shows typical SEM photomicrographs of cross sections of two V-4Cr-4Ti alloy specimens after a double $\mathrm{Ca}$ deposition/oxidation treatment. Coating thickness in these specimens were 15 to $30 \mu \mathrm{m}$. EDX analysis of the specimen surfaces showed the coatings to be $\mathrm{CaO}$ and also revealed the virtual absence of any elements from the substrate alloy. Figure 10 shows a typical EDX spectrum of the coating surface and indicates primarily $\mathrm{Ca}$ and $\mathrm{O}$ peaks. Cross sections of several specimens were analyzed as a function of depth for constituent elements of the coating and substrate. Depth profiles for two of the coated specimens are shown in Fig. 11; the profiles in indicate coating thicknesses of 16 and $34 \mu \mathrm{m}$. The coating composition 

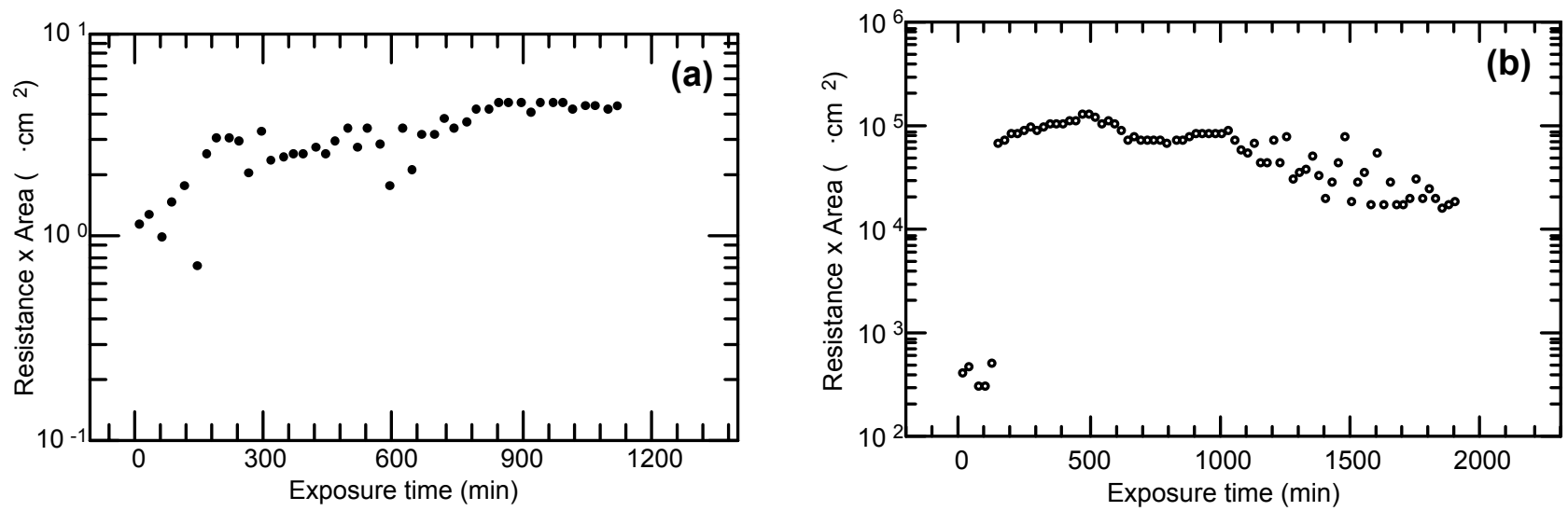

Fig. 8. Product of resistance times area as a function of time at $546^{\circ} \mathrm{C}$ for $\mathrm{V}-4 \mathrm{Cr}-4 \mathrm{Ti}$ alloy with (a) $\mathrm{Ca}$ deposition/oxidation and (b) $\mathrm{Ca}$ deposition/oxidation/Ca deposition.
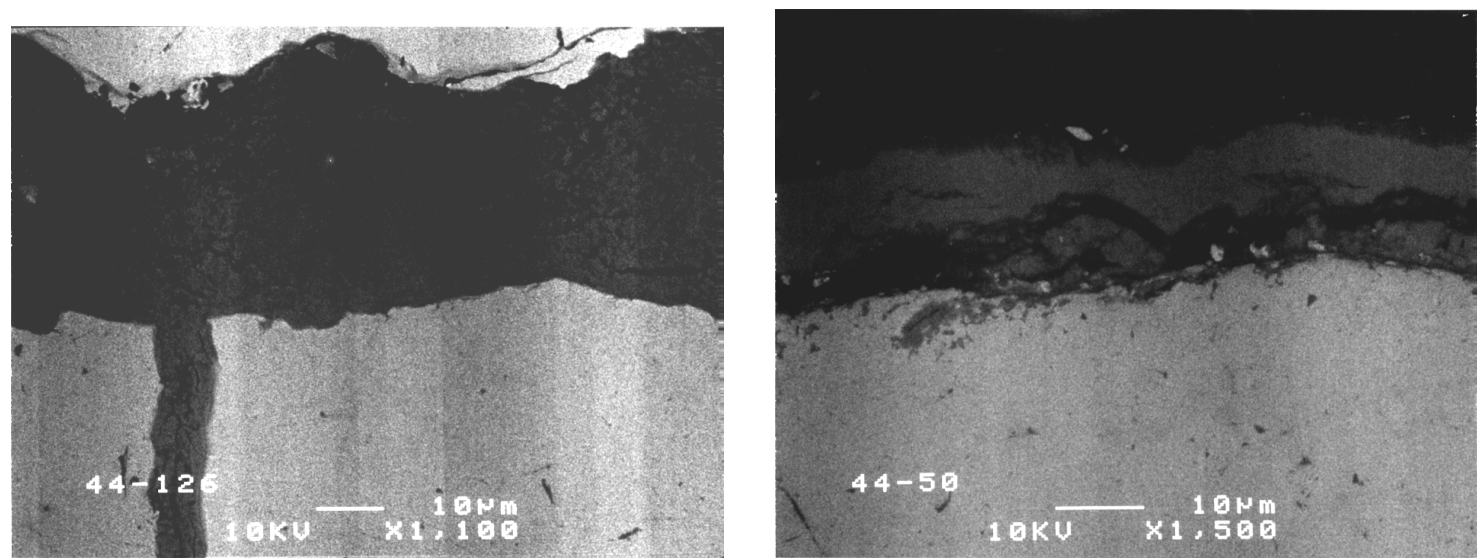

Fig. 9. SEM photomicrographs of cross sections of two V-4Cr-4Ti alloy specimens after double Ca deposition/oxidation treatment.

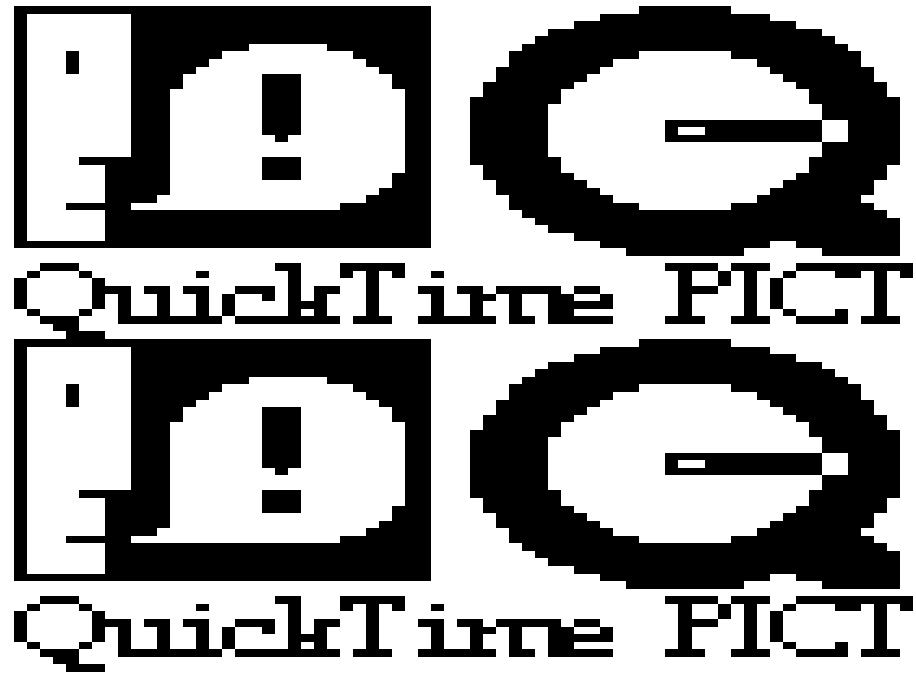

Fig. 10. EDX spectrum of surface of V-4Cr-4Ti alloy specimen after double Ca deposition/oxidation treatment. 

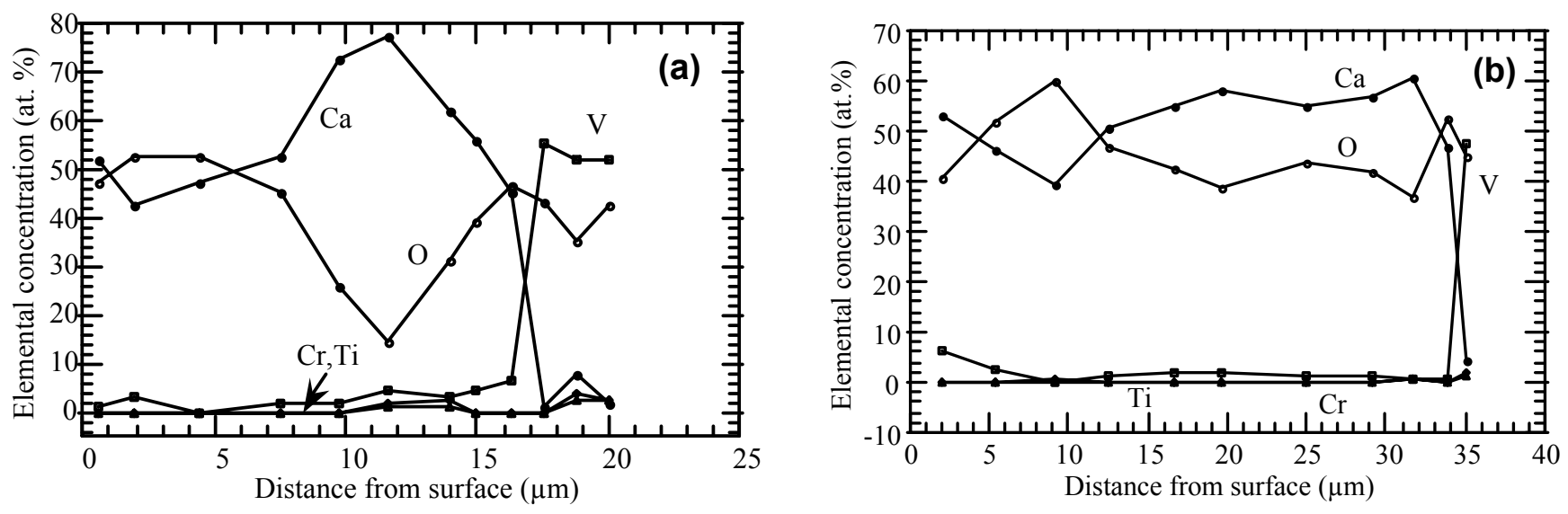

Fig. 11. Elemental concentrations as a function of coating thickness for $\mathrm{V}-4 \mathrm{Cr}-4 \mathrm{Ti}$ alloy specimens after double $\mathrm{Ca}$ deposition/oxidation treatment: coating thickness (a) $16 \mu \mathrm{m}$; (b) $34 \mu \mathrm{m}$.

was predominantly $\mathrm{CaO}$ in both specimens, and negligible amounts of substrate elements were detected in the coating region. The difference in scale thickness between the two specimens is due to the proximity of different specimens in the Ca pack. Both specimens, after double Ca and oxidation treatment, were exposed to Li of normal purity at $500^{\circ} \mathrm{C}$ for $68 \mathrm{~h}$.

To examine the stability of the coating and its electrical resistivity at elevated temperature, a two-probe method was used to measure resistance in some of the coated specimens at temperatures up to $\square 700^{\circ} \mathrm{C} .{ }^{8-10}$ The variation in the product of resistance times area (i.e., $\mathrm{R} \mathrm{x}$ A, which is equivalent to the product of resistivity times coating thickness) as a function of temperature obtained on specimens of $\mathrm{V}-4 \mathrm{Cr}-4 \mathrm{Ti}$ alloy with $\mathrm{Ca}$ deposition/oxidation and with $\mathrm{Ca}$ deposition/oxidation and redeposition of $\mathrm{Ca}$ was discussed in Ref. 9. Those results showed that the as-coated specimen (with a double $\mathrm{Ca}$ and oxidation treatment) had resistance values of $10^{4}$ to $10^{5} \square \cdot \mathrm{cm}^{2}$. Resistance measurements were also made on specimens that were double $\mathrm{Ca} /$ oxidation treated and subsequently exposed to liquid Li of normal purity at $500^{\circ} \mathrm{C}$ for $68 \mathrm{~h}$. Figure 12 shows the variation in $\mathrm{R} \mathrm{x}$ A as a function of temperature obtained on a CaO-coated and Li-exposed specimen of $\mathrm{V}-4 \mathrm{Cr}-4 \mathrm{Ti}$ alloy. The figure shows that $\mathrm{R} \times \mathrm{A}$ values are $>10^{7}$ $\square \cdot \mathrm{cm}^{2}$ from room temperature to $200^{\circ} \mathrm{C}$; the value gradually decreases to $\square 5 \times 10^{6} \square \cdot \mathrm{cm}^{2}$ as temperature is increased from 200 to $540^{\circ} \mathrm{C}$. The specimen was maintained isothermally at $\square 540^{\circ} \mathrm{C}$ for $\square 6 \mathrm{~h}$, after which it was further heated to $\square 700^{\circ} \mathrm{C}$. Even at $700^{\circ} \mathrm{C}$, the specimen exhibited an R x A value of $10^{4} \square \cdot \mathrm{cm}^{2}$, at least two orders of magnitude higher than that required in a fusion device using a Li blanket. Figure 13 shows variation in $\mathrm{R} \times \mathrm{A}$ as a function of exposure time obtained on a CaO-coated and $\mathrm{Li}$-exposed specimen of $\mathrm{V}-4 \mathrm{Cr}-4 \mathrm{Ti}$ alloy. It is evident that the coating had R x A values of $10^{5}$ and $10^{4} \square \cdot \mathrm{cm}^{2}$ at 541 and $702^{\circ} \mathrm{C}$, respectively. 


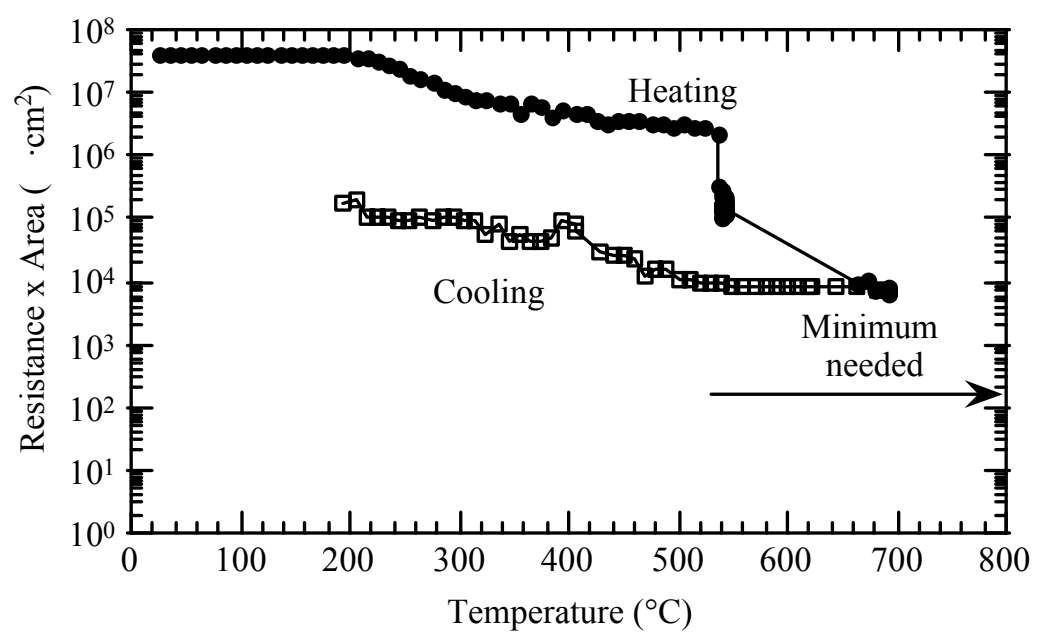

Fig. 12. Product of resistance times area as a function of temperature for $\mathrm{V}-4 \mathrm{Cr}-4 \mathrm{Ti}$ alloy with double $\mathrm{Ca}$ deposition and oxidation after 68 -h exposure in $\mathrm{Li}$ environment at $500^{\circ} \mathrm{C}$.

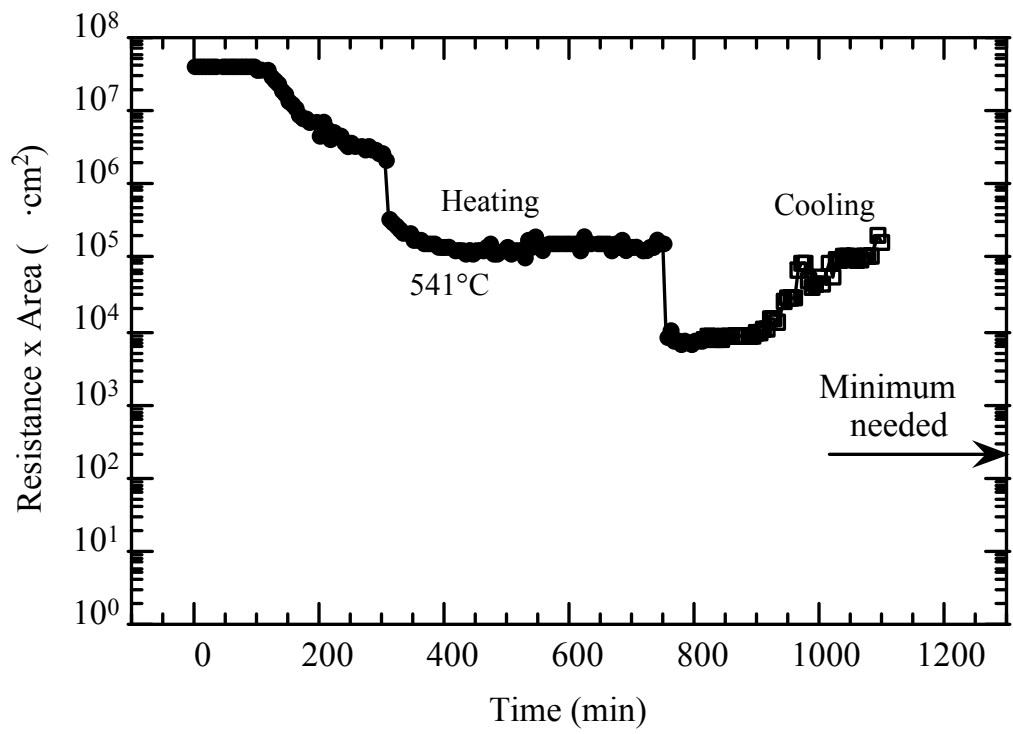

Fig. 13. Product of resistance times area as a function of time for $\mathrm{V}-4 \mathrm{Cr}-4 \mathrm{Ti}$ alloy with double $\mathrm{Ca}$ deposition/oxidation after 68-h exposure in $\mathrm{Li}$ environment at $500^{\circ} \mathrm{C}$.

\section{Coating Development In-Situ in Li-Ca Mixture}

The primary mechanism of coating formation in-situ in Li involves reactions of oxygen from the vanadium alloy with calcium dissolved in the lithium. Variables in this reaction include temperature, time, oxygen concentration in vanadium alloy, and calcium concentration in Li. ${ }^{11-13}$ Scoping tests were conducted by exposing small coupons of $\mathrm{V}$ alloys at various temperatures to Li containing various concentrations (2-50 at \%) of $\mathrm{Ca}$. It was generally found 
that increasing the $\mathrm{O}$ concentration in this surface of $\mathrm{V}$ by exposure to low-pressure $\mathrm{O}$ environments before exposure to the $\mathrm{Li}-\mathrm{Ca}$ alloy produced thicker oxide reaction products. A range of conditions (temperature, oxygen pressure, and time) were investigated to determine which conditions provided better coating characteristics. In the initial investigations, $\mathrm{CaO}$ coatings were obtained by reacting $\mathrm{V}$ alloy coupons in Li-Ca in small capsules $\left(<100 \mathrm{~cm}^{3}\right)$ at $400-1000^{\circ} \mathrm{C}$. $\mathrm{CaO}$ coatings $\square 10 \mu \mathrm{m}$ thick were successfully formed on $\mathrm{V}$ alloys as shown in Figs. 14 and 15. In this case, microcracks were observed at room temperature; however, spallation of the coating was not observed.

Specimens of V-4Cr-4Ti alloy with a coating of $\mathrm{CaO}$ developed in-situ in an $\mathrm{Li}-\mathrm{Ca}$ environment were examined to characterize the microstructure and coating resistance. Resistance measurements were made on in-situ-coated specimens (without alcohol wash to clean the $\mathrm{Li} / \mathrm{Li}_{2} \mathrm{O}$ of the specimen surface) as a function of temperature in an Ar environment external to Li. Figure 16 shows an SEM photomicrograph of the surface of a CaO-coated V-4Cr-4Ti alloy specimen after exposure to an $\mathrm{Li}$ environment. The surface region consisted of $\mathrm{Li}_{2} \mathrm{O}$ as the outer layer (characterized by a rough, light-toned texture) and a Ca-enriched inner layer (a smooth gray texture). Figure 17 shows the variation in $\mathrm{R} \mathrm{x} \mathrm{A}$ as a function of temperature for this specimen. The value for $\mathrm{R} \times \mathrm{A}$ at temperatures up to $\square 300^{\circ} \mathrm{C}$ is more than the minimum
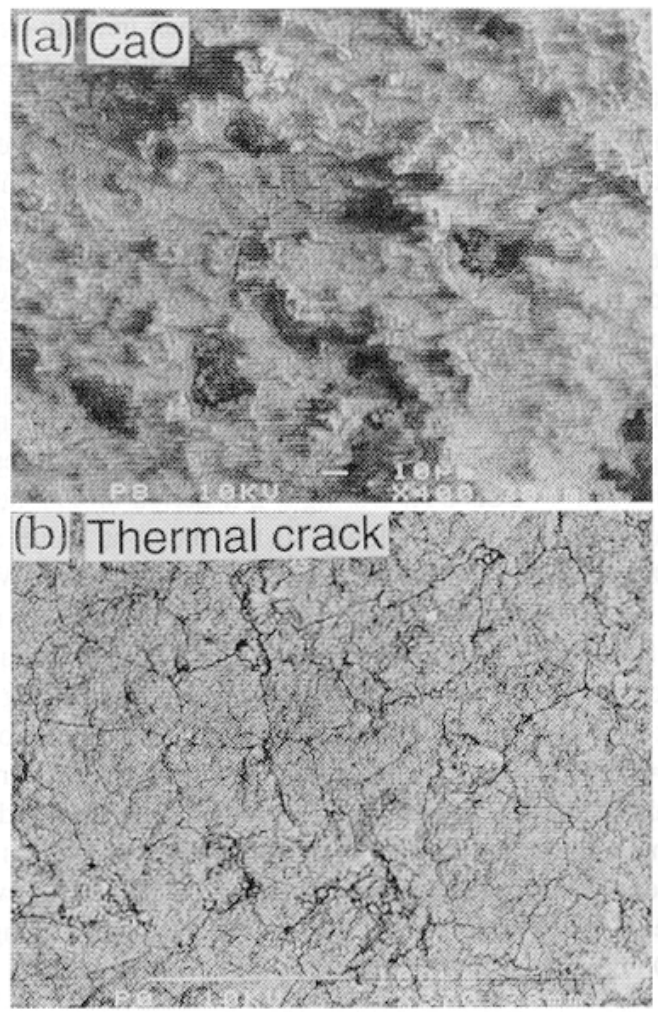

Fig. 14. (a) SEM photomicrograph of surface of $\mathrm{CaO}$ coating, and (b) microcracks in coating. 

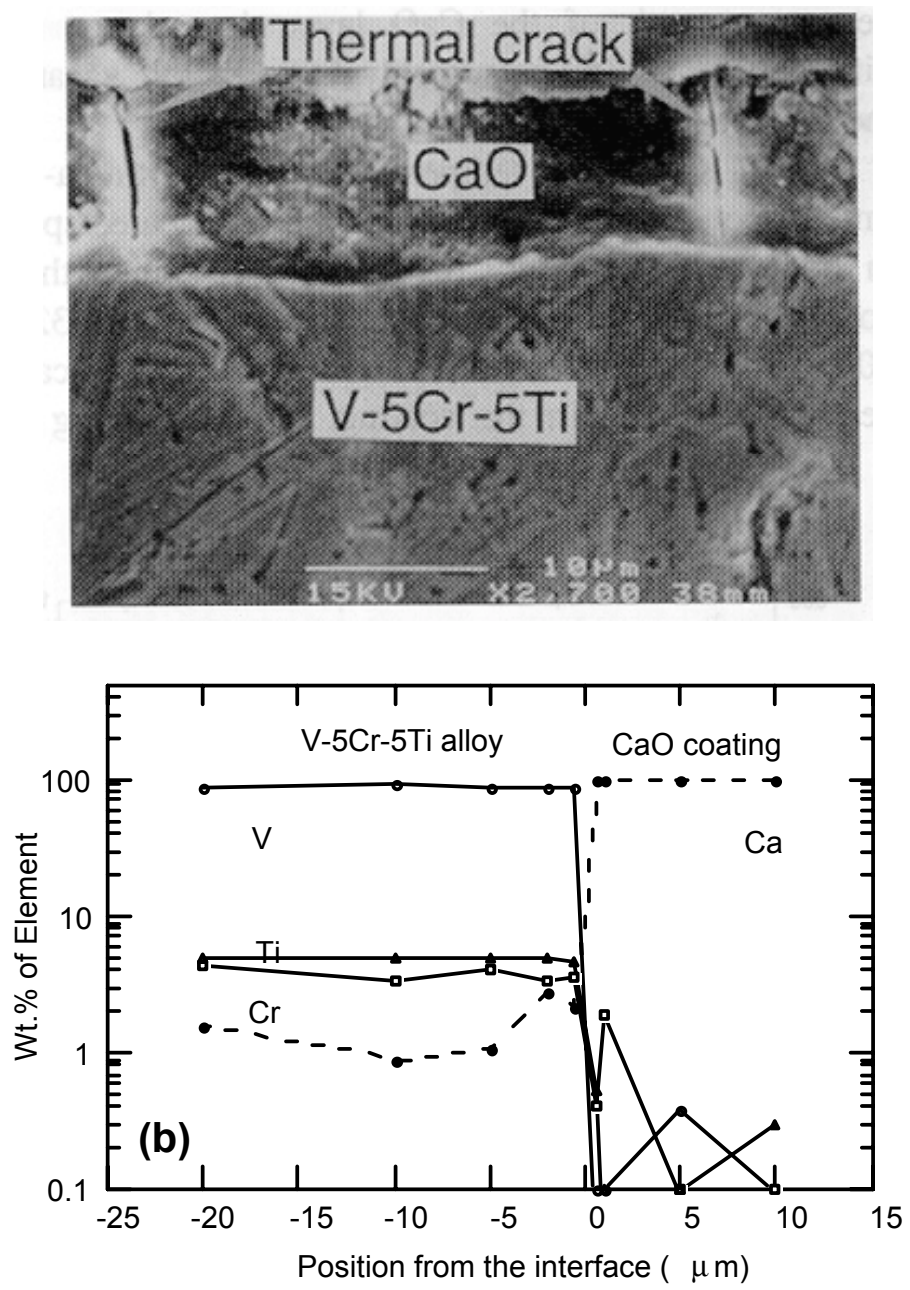

Fig. 15. (a) SEM photomicrograph of cross section and (b) EDX depth profiles (bottom) of V, $\mathrm{Cr}$, Ti, and $\mathrm{Ca}$ at $\mathrm{CaO} / \mathrm{V}-5 \mathrm{Cr}-5 \mathrm{Ti}$ interface of coating formed at $400^{\circ} \mathrm{C}$.

needed, but the value decreases substantially as temperature increases to $614^{\circ} \mathrm{C}$. Maintaining the specimen at $614^{\circ} \mathrm{C}$ for extended time periods seems to improve the resistance of the coating; further increase in temperature to $713^{\circ} \mathrm{C}$ results in a slight reduction in resistance. In the cooling part of the cycle, the resistance values are at least two orders of magnitude higher than in the heating part of the cycle, with a probable inference of coating consolidation/densification and subtle change in chemistry of the coating during the heating part of the cycle.

Figure 18 shows the variation in $\mathrm{R} \times \mathrm{A}$ value as a function of time for the same coated specimen. The results indicate that the resistance values for the coating in the cooling part of the cycle are substantially higher than in the heating part of the cycle, even though the coating is 


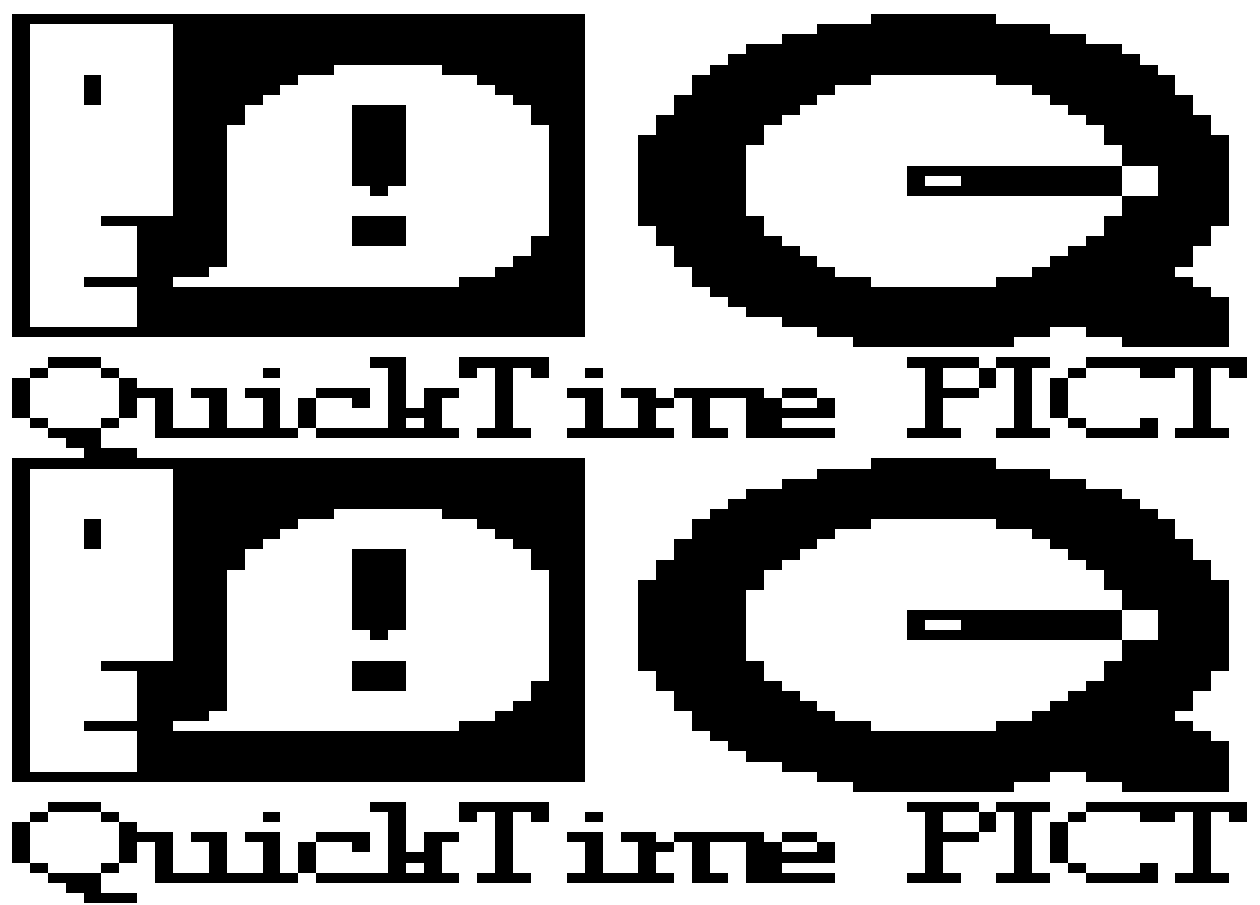

Fig. 16. SEM photomicrograph of surface of V-4Cr-4Ti alloy specimen with $\mathrm{CaO}$ coating developed in-situ in Li-Ca mixture.

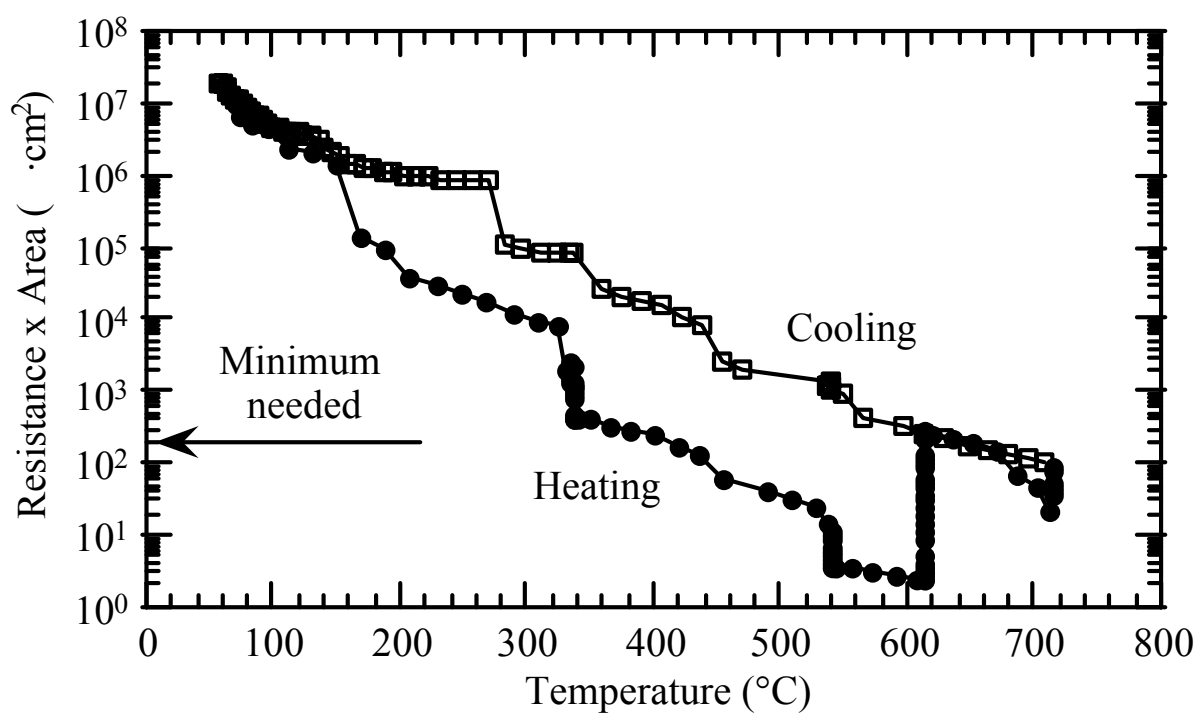

Fig. 17. Product of resistance times area as a function of temperature for $\mathrm{V}-4 \mathrm{Cr}-4 \mathrm{Ti}$ alloy with $\mathrm{CaO}$ coating developed in-situ in Li-Ca environment. 


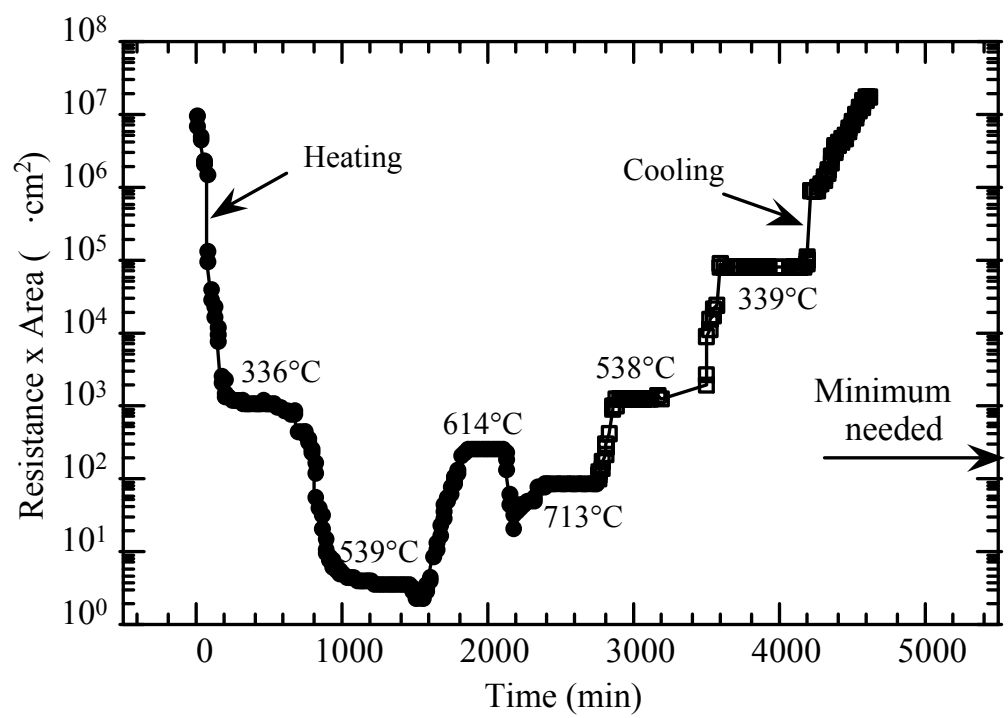

Fig. 18. Product of resistance times area as a function of time for $\mathrm{V}-4 \mathrm{Cr}-4 \mathrm{Ti}$ alloy with $\mathrm{CaO}$ coating developed in-situ in Li-Ca environment.

maintained nominally at the same temperature (e.g., 336/339 and 539/538 ${ }^{\circ} \mathrm{C}$ ) during both the heating and cooling portions of the cycle.

In-situ measurements of electrical resistivity of coated samples showed high resistance values when exposed to $\mathrm{Li}-0.5 \mathrm{wt} . \% \mathrm{Ca}$ for extended periods at elevated temperatures, e.g., $>200 \mathrm{hr}$ at $435^{\circ} \mathrm{C}$ (see Fig. 19). This coating was obtained by exposing the alloy to high-purity $\operatorname{Ar}(\square 10 \mathrm{ppm} \mathrm{O})$ at $650^{\circ} \mathrm{C}$ for $17 \mathrm{~h}$ to oxygenate the surface, followed by a 17-h exposure to $50 / 50$ at.\% $\mathrm{Li}-\mathrm{Ca}$ alloy at $400^{\circ} \mathrm{C}$ in small-capsule tests. Generally positive results were obtained in several tests of this type. Additional tests were conducted to evaluate the thermal cycling/thermal shock resistance of these coatings. Results obtained by thermal cycling the Li$\mathrm{Ca}$ vessel indicated ceramic resistivity behavior (increase in resistivity with a decrease in temperature) followed initially by a sharp decrease in resistivity. The decrease in resistivity was attributed to cracking of the coating (see Fig. 20). An increase in temperature was followed by an increase in resistance, suggesting self-healing of the cracks. These types of tests were duplicated with similar results. Significant resistances (R x A $>1000 \Omega \cdot \mathrm{cm}^{2}$ ) were achieved from these self-healing experiments; however, the resistance values were typically much lower than the initial high resistance values.

Results obtained in these experiments were considered sufficiently encouraging to initiate tests on a larger scale, i.e., a static test vessel containing $\square 3 \mathrm{~L}$ of Li-Ca alloy. These tests were conducted with rod-type (pencil) specimens with rounded ends in an attempt to minimize residual liquid metal which adhered to the end of the specimens and possible cracking at sharp 


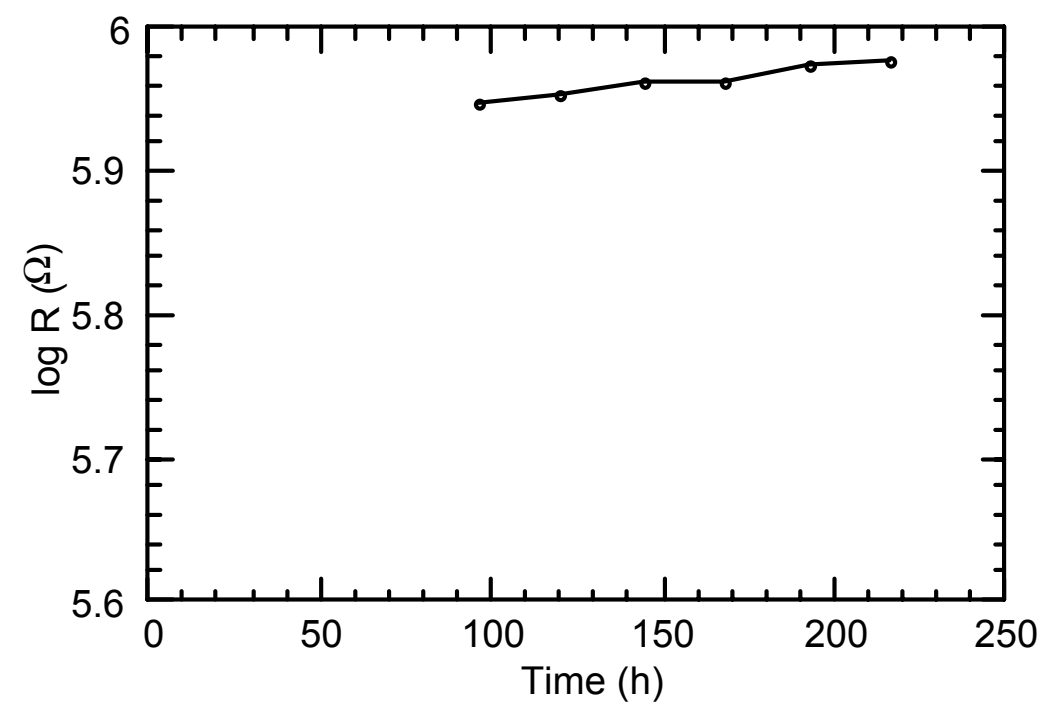

Fig. 19. Log $\mathrm{R}$ vs. time of $\mathrm{CaO}$ coating formed by exposure of $\mathrm{V}-5 \mathrm{Cr}-5 \mathrm{Ti}$ alloy to $\mathrm{Ar}$ at $650^{\circ} \mathrm{C}$ for $17 \mathrm{~h}$ and to $85 \mathrm{wt} . \% \mathrm{Ca}-\mathrm{Li}$ at $400^{\circ} \mathrm{C}$ for $17 \mathrm{~h}$. Resistance measured in 0.5 wt.\% Ca-Li at $435^{\circ} \mathrm{C}$.

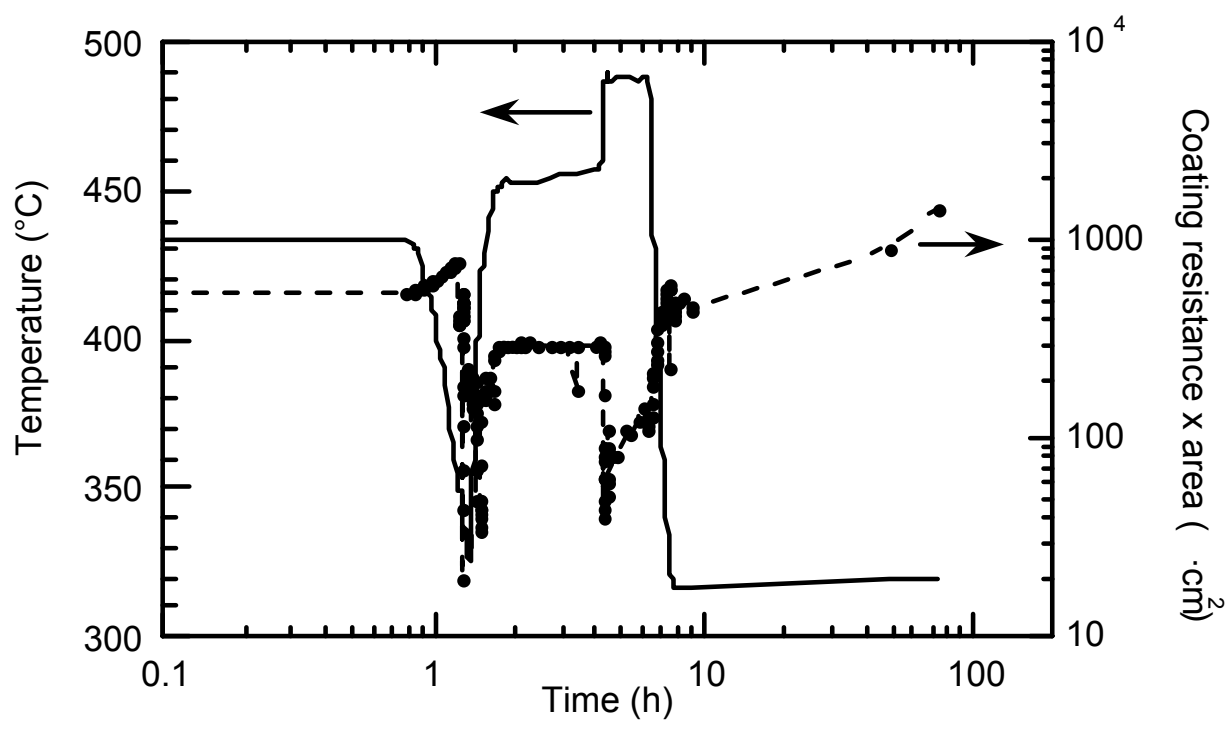

Fig. 20. Temperature and product of resistance times area vs. time during thermal cycling. 
corners. Vanadium alloy specimens exposed to $\mathrm{Li}-\mathrm{Ca}$ at temperatures of $400-500^{\circ} \mathrm{C}$ exhibited a modest increase in resistance with time as shown in Fig. 21, indicating formation of a very thin insulating coating. A range of coating parameters (temperatures, exposure time, Ca content, and preexposure oxidation) were investigated. These tests were conducted primarily with only a few percent $\mathrm{Ca}(\leq 4$ wt.\%) in lithium; however, the general procedure remained the same; viz., oxygenate the vanadium alloy surface, expose the specimen to the $\mathrm{Li}-\mathrm{Ca}$ alloy, gas phase oxidation of the Ca coating in most cases, and subsequent compatibility or resistance testing in the $\mathrm{Li}$ (usually with low $\mathrm{Ca}$ content to provide for self-healing). These test generally were less successful than the previous tests, typically exhibiting thinner coatings and much lower resistance values from the in-situ measurements.

Resistance measurements by probes indicated high resistance over most of the surface at room temperature, whereas many specimens exhibited very low resistance immediately upon insertion into the liquid. In several cases, we obtained relatively high resistance initially upon exposure to Li-Ca with subsequent shorting (low resistance) after $\square 1 \mathrm{hr}$ exposure (Fig. 22). In other cases, as shown in Fig. 23, the insulator coatings exhibited high resistance (R x A $\square$ $10^{10} \Omega \cdot \mathrm{cm}^{2}$ ) for periods of several hundred hours, including changes in temperature. An EDX profile for this case is shown in Fig. 24. Similar resistance measurements were made using a liquid gallium bath. Results were typically similar. For the case of gallium testing, we covered isolated defects in the coating with a resistive material. We obtained very high resistance $(>100$ $\mathrm{k} \Omega$ ) during testing in gallium. In a few cases, as illustrated in Fig. 25, only a few very small defects were present over most of the specimens. Two positive results were the high resistivity of the coating and the sensitivity of the gallium continuity test procedure to extremely small defects. We have not resolved the cause of these defects, but their presence is partially attributed to the thinner coatings $(2-3 \mu \mathrm{m})$ compared to earlier experiments with coatings typically $5-10 \mu \mathrm{m}$ thick.

An important result obtained in the analysis of the coatings involved composition, in particular the amount of $\mathrm{V}$ in the insulator coating. High resistivity was observed for $\mathrm{Ca} / \mathrm{V}$ ratios above 0.8, whereas significantly lower resistivities were obtained for coatings when $\mathrm{V}$ concentrations significantly exceeded 0.2 of the cation concentration.

\section{DEVELOPMENT OF AIN COATINGS}

Several possible approaches are being examined to develop an AlN coating on the candidate structural material, including (a) prealuminizing the surface of the material by a diffusion process and subsequently converting it to nitride in an external gas atmosphere; (b) using a physical vapor deposition process with and without bond coats; (c) applying a lowtemperature electrochemical method that involves sequential reactions; (d) prealuminizing the surface of the alloy and converting it to nitride in a high-nitrogen Li environment; (e) preexposing the material to liquid $\mathrm{Al}$ and converting it to nitride in $\mathrm{Li}$; (f) in-situ forming of an AlN coating in $\mathrm{Li}$ with high thermodynamic activities for $\mathrm{Al}$ and $\mathrm{N}$; and $(\mathrm{g})$ prealuminizing 


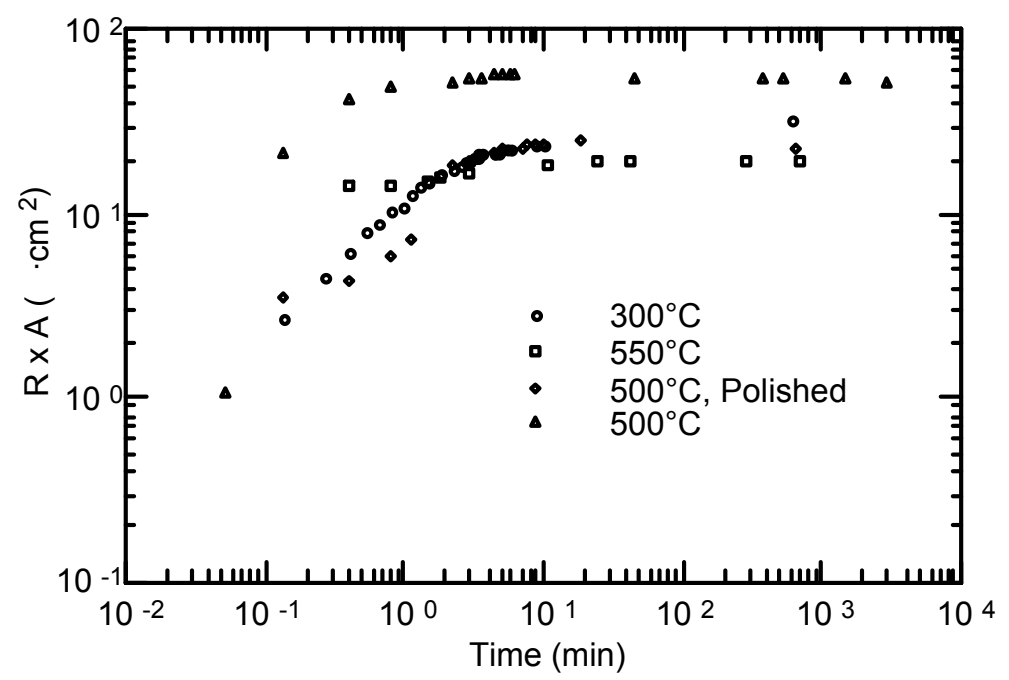

Fig. 21. In-situ measured product of resistance times area during $\mathrm{Ca}$ coating on O-charged $\mathrm{V}-4 \mathrm{Cr}$ 4Ti alloy.

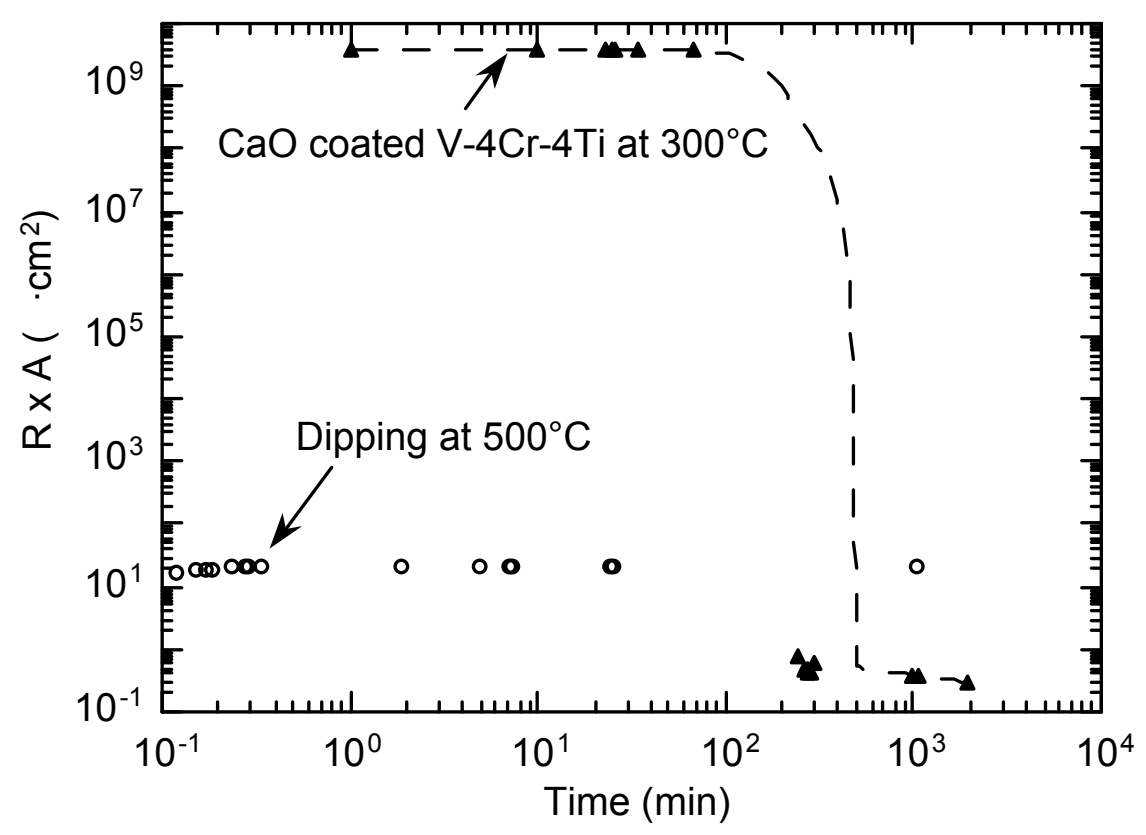

Fig. 22. In-situ measured $\mathrm{R} \times \mathrm{A}$ vs. time for O-charged (open symbol) and previously coated (closed symbol) $\mathrm{V}-4 \mathrm{Cr}-\mathrm{Ti}$ specimens in $\mathrm{Li}-2$ at.\% $\mathrm{Ca}$ at $300^{\circ} \mathrm{C}$. 


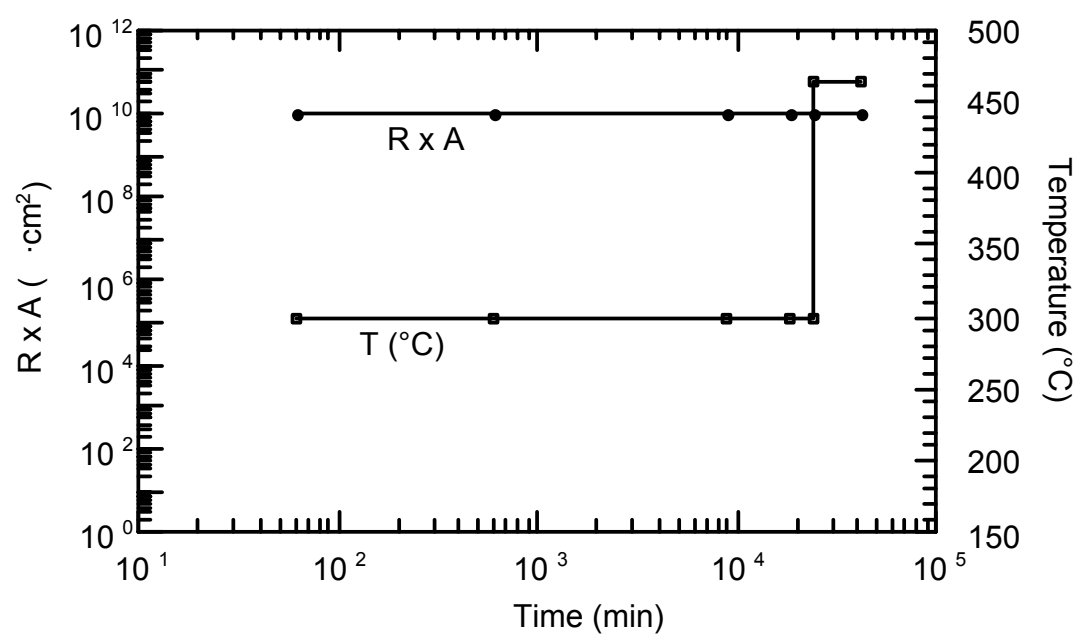

Fig. 23. In-situ R x A (solid symbol) and temperature (open symbol) vs. time for $\mathrm{CaO}$ coating on V-15Cr-5Ti.

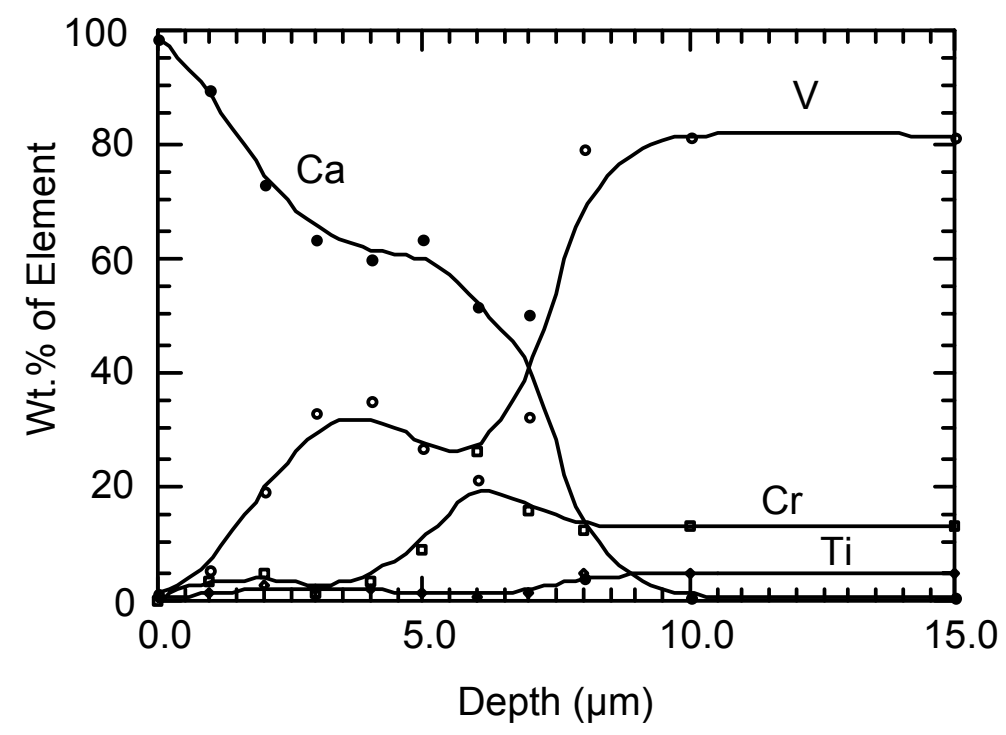

Fig. 24. EDX analysis as a function of depth for $\mathrm{CaO} / \mathrm{V}-15 \mathrm{Cr}-5 \mathrm{Ti}$ specimen after $700 \mathrm{~h}$ exposure to $\mathrm{Li}-2$ at. $\% \mathrm{Ca}$ at $300-464^{\circ} \mathrm{C}$.

specimens of structural material and nitriding them with an $\mathrm{N}_{2}$ cover gas during $\mathrm{Li}$ exposure. ${ }^{14,15}$ This report presents research highlights on coatings developed by the physical vapor deposition (PVD) technique and elaborates on recently developed information on the electrical resistivity of bulk AlN and AlN coatings before and after exposure to Li. 


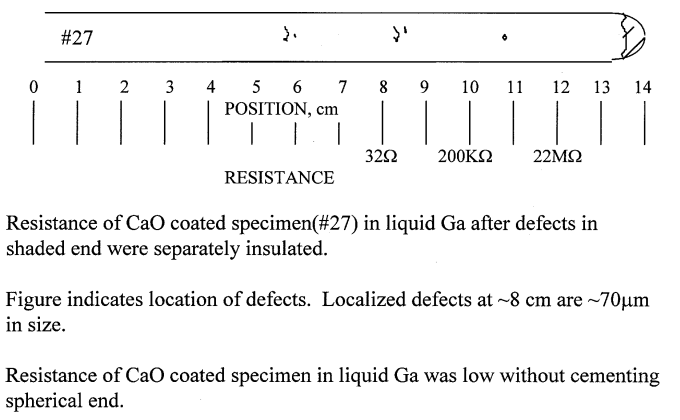

Resistance of $\mathrm{CaO}$ coated specimen in liquid $\mathrm{Ga}$ was low without cementing
spherical end.

Fig. 25. Pencil specimens.

PVD was used for development of AIN coatings on both bare and prealuminized specimens of V-5Cr-5Ti alloy. Aluminum nitride was sputter-deposited reactively. That is, an aluminum target was sputtered in a partial pressure of high-purity nitrogen, with argon as the primary sputtering gas. Because the process takes place in a vacuum chamber and uses high-purity reactants, the coating product should also be very pure. The process takes place at a relatively low temperature, generally not above $\square 250^{\circ} \mathrm{C}$. The chamber was initially pumped down to $2 \mathrm{x}$ $10^{-6}$ torr before coating was started. Specimens of both bare and prealuminized V-5Cr-5Ti and the Al target were sputter-cleaned for 6 min with high-purity argon at a flow rate of $45 \mathrm{~cm}^{3} / \mathrm{min}$ and a chamber pressure of 20 mtorr. Subsequently, $\mathrm{AlN}_{\mathrm{X}}$ was sputter-deposited with a $1200-\mathrm{W}$ $\mathrm{RF}$ power source for $10 \mathrm{~h}$ in an argon-nitrogen gas mixture at a chamber pressure of 23 mtorr. The sputtered specimens were cooled in vacuum overnight, and the second side of the specimens was then coated the same way.

The as-deposited AIN layers were fairly compact and of uniform thickness, in the range of 8-12 $\mu \mathrm{m}$. X-ray diffraction analysis showed hexagonal AlN phase with a (002) orientation. No vanadium nitride was detected because the substrate was at $<200^{\circ} \mathrm{C}$ during the coating process. Even though the coatings were fairly adherent, early exposures of these coated specimens in Li resulted in complete disappearance of the coating layer by either spallation or dissolution. As a result, the coated specimens were given a thermal hardening treatment at $700-900^{\circ} \mathrm{C}$ prior to exposure in Li. Figure 26 shows SEM photomicrographs of AlN-coated V-alloy specimens after 
hardening treatment at $900^{\circ} \mathrm{C}$ for $110 \mathrm{~h}$. Figures $26 \mathrm{a}$ and $26 \mathrm{~b}$ show the hardened layers on bare and prealuminized $\mathrm{V}$-alloy substrate. X-ray diffraction analysis of these heat-treated specimens also showed hexagonal AlN phase with (002) orientation, but traces of the $\mathrm{V}_{2} \mathrm{~N}$ phase were noted because of a reaction between $\mathrm{AIN}$ and $\mathrm{V}$ at the coating/substrate interface. Figures 26c and $26 \mathrm{~d}$ show the hardened coatings on bare $\mathrm{V}$-alloy substrate from another source. The specimen in Fig. 26c had an intermediate layer of TiN, sputter-deposited to minimize possible reaction between AIN and Ti in the alloy.

Several AlN-coated V-alloy specimens were exposed to liquid $\mathrm{Li}$ at $300^{\circ} \mathrm{C}$, after which detailed microstructural analyses of all specimens, and X-ray diffraction analysis of selected specimens, were performed. Further, electrical resistance was measured on several of the Liexposed AlN-coated specimens. Figure 27 is an SEM photomicrograph, in cross section, of an AlN-coated V-5Cr-5Ti alloy specimen after $430 \mathrm{~h}$ exposure at $300^{\circ} \mathrm{C}$ to an Li environment in which argon-nitrogen gas was bubbled for $24 \mathrm{~h}$. Figure 28 shows EDX depth profiles for Al, N, $\mathrm{V}, \mathrm{Cr}$, and Ti, AlN-coated, prealuminized V-5Cr-5Ti alloy specimen after $430 \mathrm{~h}$ exposure at $300^{\circ} \mathrm{C}$ to an Li environment in which argon-nitrogen gas was bubbled for $24 \mathrm{~h}$. EDX analysis
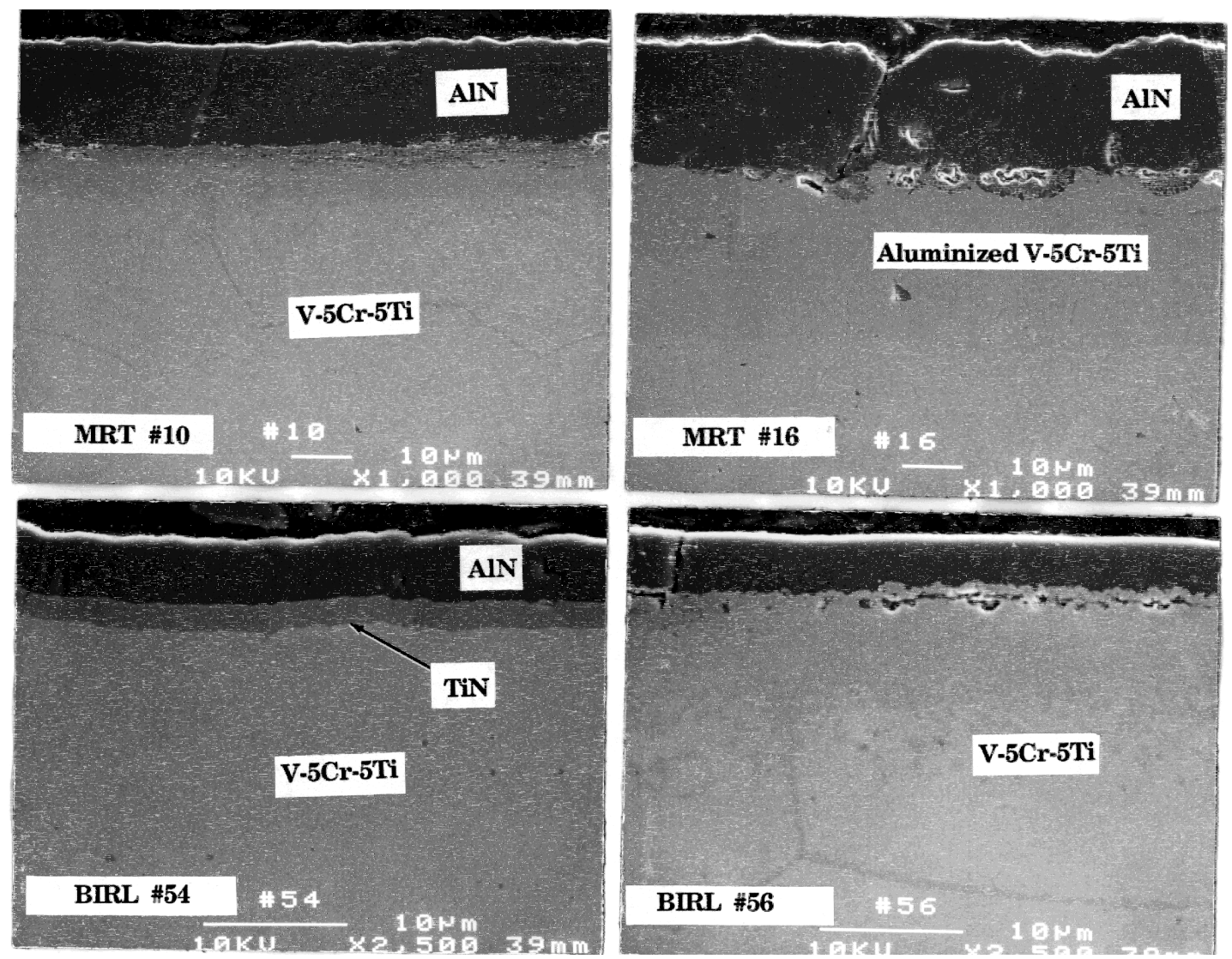

Fig. 26. SEM photomicrographs of AlN-coated V-alloy specimens after hardening treatment at $900^{\circ} \mathrm{C}$ for $110 \mathrm{~h}$. (a) and (b) show the hardened layers on bare and prealuminized V-alloy substrate; (c) and (d) show the hardened coatings on bare $\mathrm{V}$-alloy substrate from another source. 


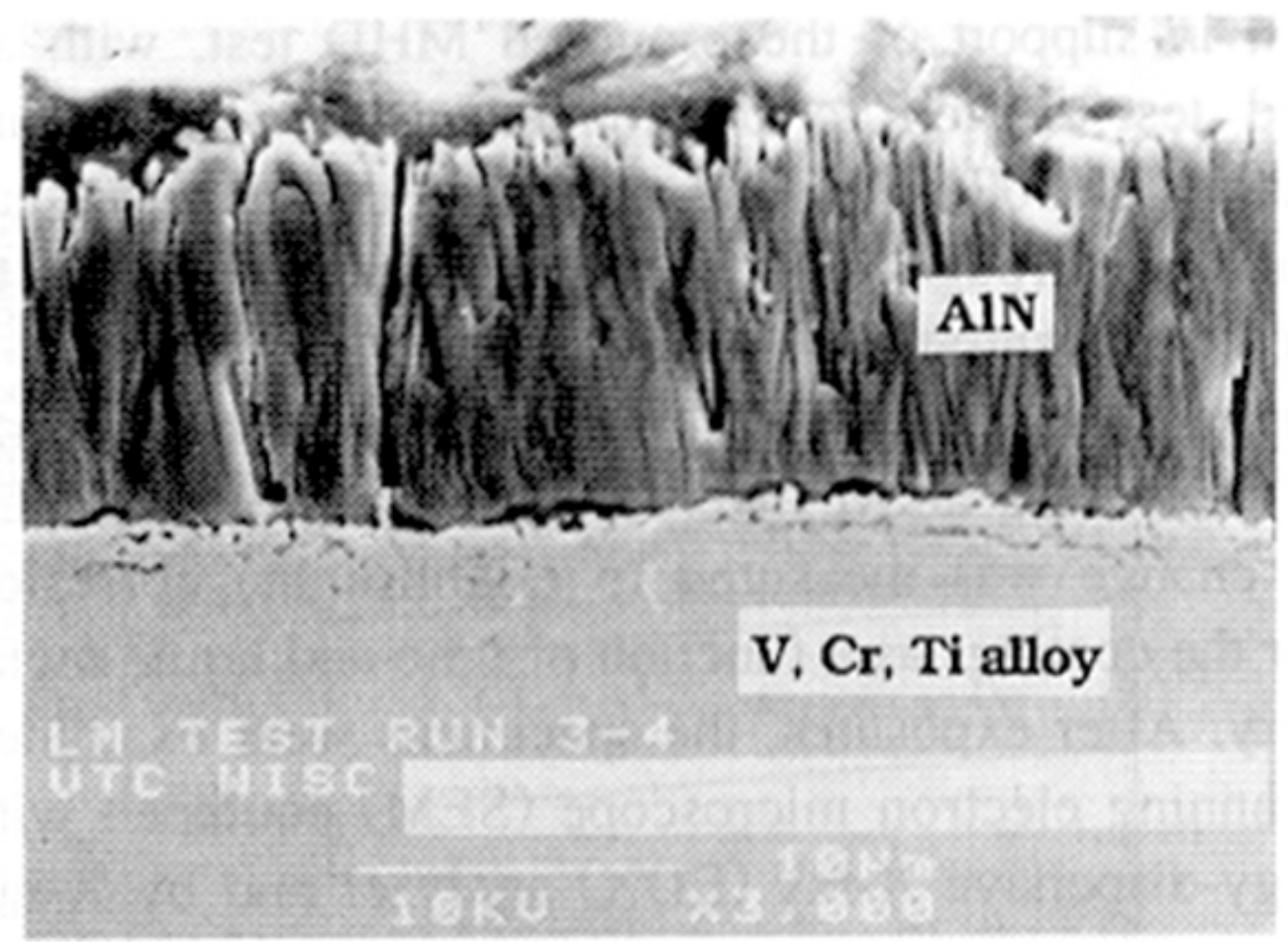

Fig. 27. SEM photomicrograph in cross section of AlN-coated V-5Cr-5Ti alloy specimen after $430 \mathrm{~h}$ exposure to $\mathrm{Li}$ environment at $300^{\circ} \mathrm{C}$.

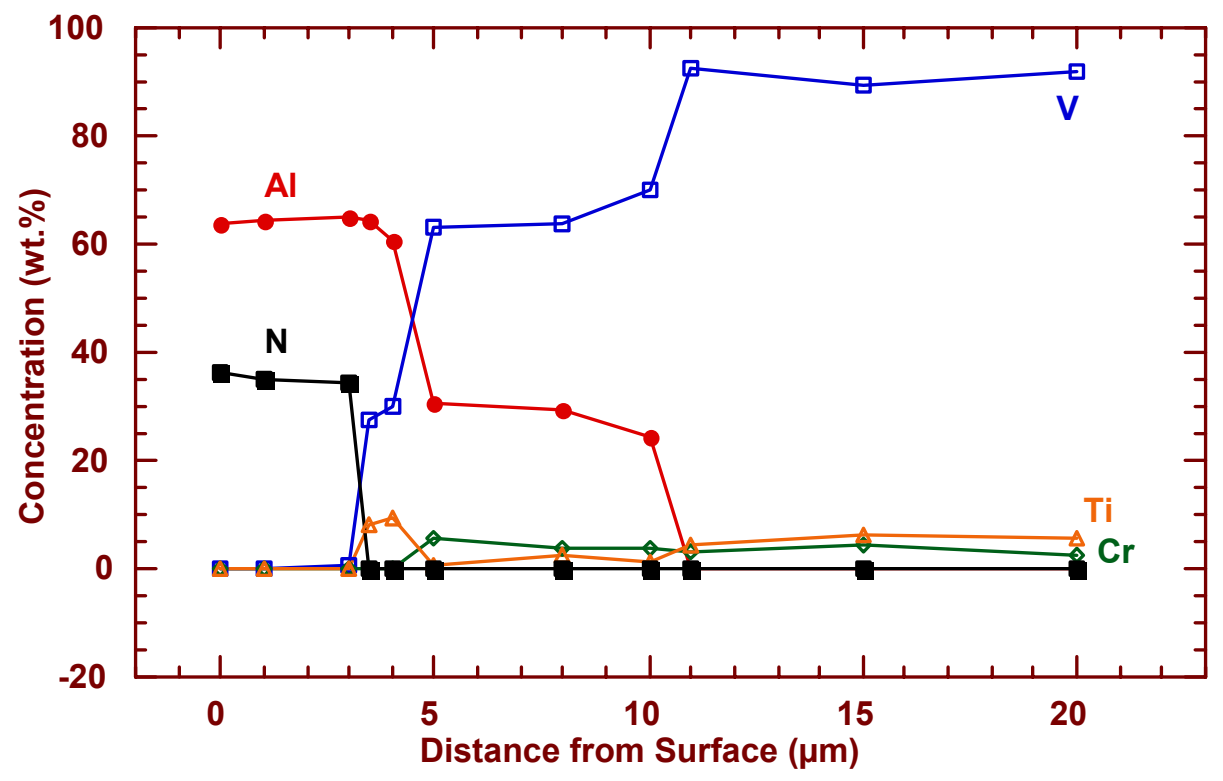

Fig. 28. EDX depth profiles for Al, N, V, Cr, and Ti for V-5Cr-5Ti alloy specimen after $430 \mathrm{~h}$ exposure to $\mathrm{Li}$ environment at $300^{\circ} \mathrm{C}$. 
shows that the coating is predominantly $\mathrm{Al}$ and $\mathrm{N}$, with almost no contamination from either the impurities in $\mathrm{Li}$ or the substrate constituents. Additional information on the AlN coating development and its compatibility in a Li environment was presented in earlier publications. ${ }^{14-16}$

Resistance measurements were made on bulk AlN samples and AlN coatings developed by $\mathrm{PVD}$, after exposure in an $\mathrm{Li}$ environment at $300^{\circ} \mathrm{C}$. Figure 29 shows the variation in $\mathrm{R} \mathrm{x} \mathrm{A} \mathrm{as} \mathrm{a}$ function of temperature for the bulk AlN specimen after exposure in an $\mathrm{Li}$ environment at $300^{\circ} \mathrm{C}$. The value for R x A is $>10^{7} \square \cdot \mathrm{cm}^{2}$ at temperatures up to $\square 300^{\circ} \mathrm{C}$, beyond which the resistance decreases but still has a value of $10^{4} \square \cdot \mathrm{cm}^{2}$ at a temperature up to $700^{\circ} \mathrm{C}$. Figure 30 shows the variation in $\mathrm{R} \times \mathrm{A}$ as a function of exposure time obtained on bulk AlN specimen after $\mathrm{Li}$ exposure. Results indicate that a fairly constant value of resistance is observed at each temperature used for the isothermal evaluation and that the values are substantially higher than needed for blanket application. But the values obtained at similar temperatures during the heating and cooling parts of the cycle are different, and additional effort is underway to address this issue.

Figure 31 shows the variation in $\mathrm{R} x \mathrm{~A}$ as a function of temperature for an AlN-coated (by PVD) $\mathrm{V}-5 \mathrm{Cr}-5 \mathrm{Ti}$ alloy specimen after exposure in an $\mathrm{Li}$ environment at $300^{\circ} \mathrm{C}$. The value for $\mathrm{R}$ $\mathrm{x} \mathrm{A}$ is $>10^{7} \square \cdot \mathrm{cm}^{2}$ at temperatures up to $\square 400^{\circ} \mathrm{C}$, beyond which resistance decreases but still has a value of $10^{5} \square \cdot \mathrm{cm}^{2}$ at a temperature as high as $700^{\circ} \mathrm{C}$. A comparison of the results in Figs. 29 and 31 shows that the electrical resistance of the AlN coating is similar, and may be even better, than that of bulk AlN material prepared by high-temperature sintering.

To examine the thermodynamic stability of AlN in Li and the possible reactions between the AlN coating and $\mathrm{O}$ in $\mathrm{Li}$, calculations were made to evaluate the regions of stability of AlN in terms of Li chemistry. It was concluded that the predominant reaction between AIN and $\mathrm{O}$ in

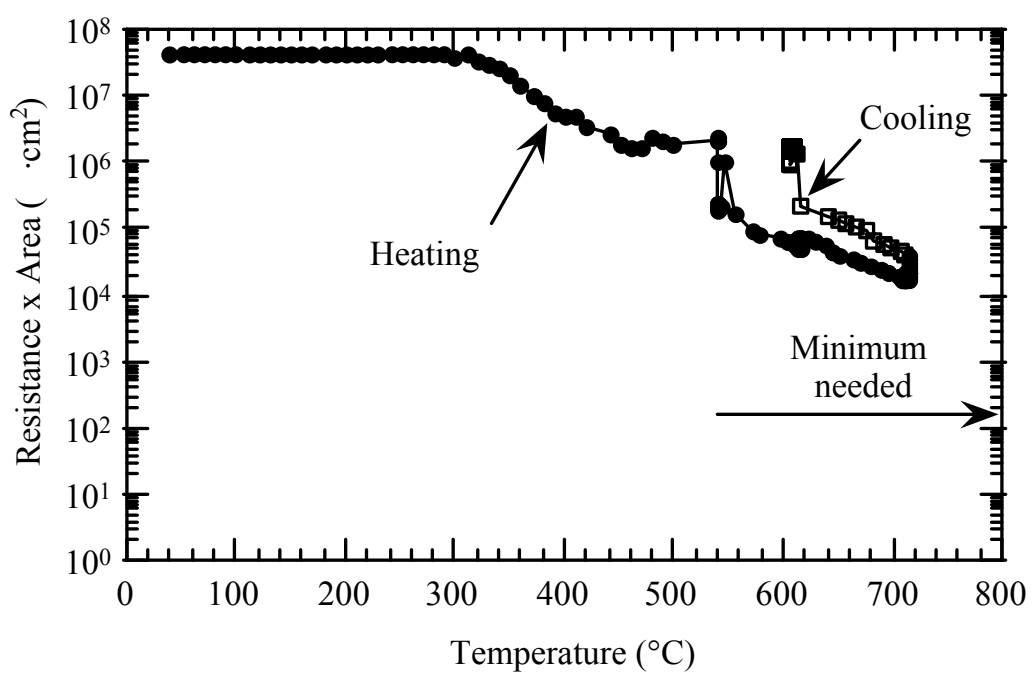

Fig. 29. Product of resistance times area as a function of temperature for bulk AlN after exposure in $\mathrm{Li}$ environment. 


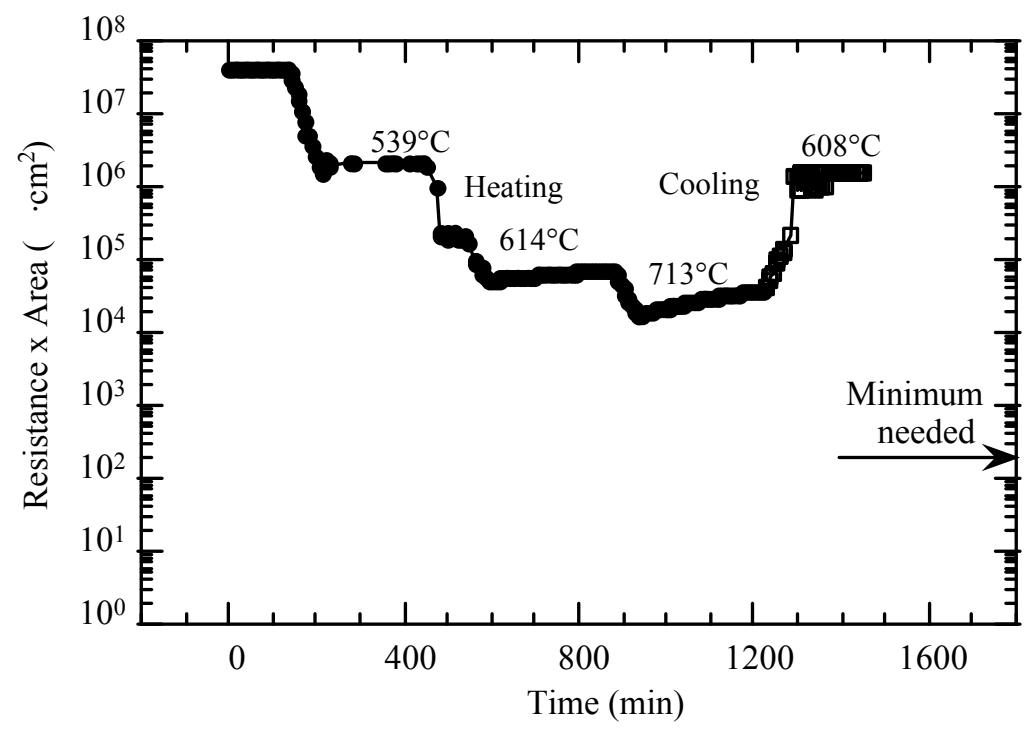

Fig. 30. Product of resistance times area as a function of time for bulk AlN after exposure in $\mathrm{Li}$ environment.

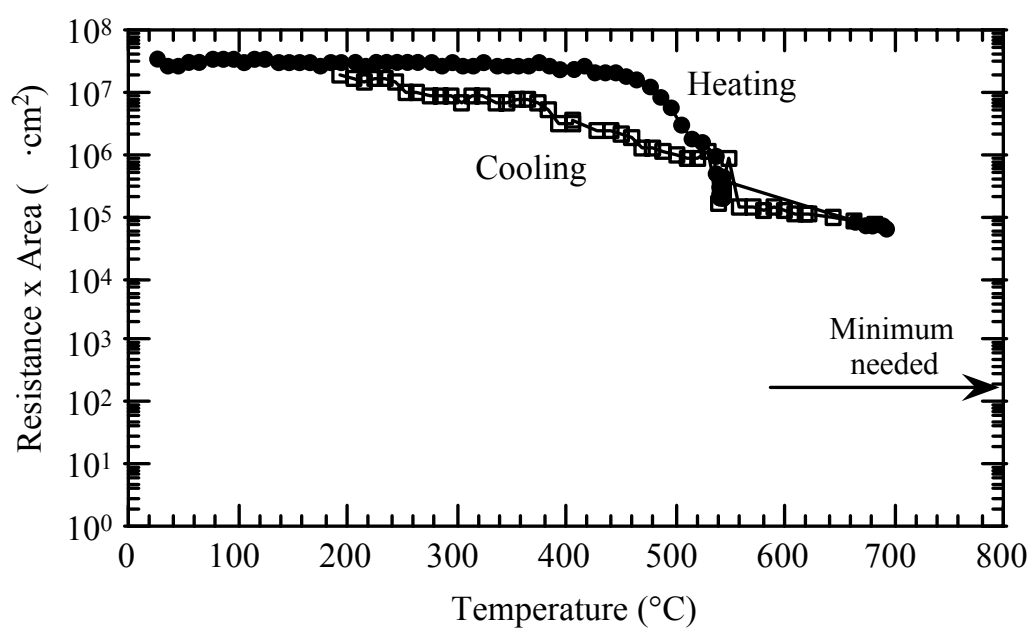

Fig. 31. Product of resistance times area as a function of temperature for $\mathrm{V}-5 \mathrm{Cr}-5 \mathrm{Ti}$ alloy with AlN coating developed by PVD, after exposure in Li environment.

lithium would lead to $\mathrm{LiAlO}_{2}$ phase and regions of stability of this phase (see Fig. 32) from the standpoint of temperature and $\mathrm{O}$ and $\mathrm{N}$ concentrations in Li was discussed in an earlier report. ${ }^{15}$ In the event that all of the AlN reacts to form $\mathrm{LiAlO}_{2}$, it is desirable to establish the electrical insulating characteristics of the reacted layer as a function of temperature. To address this issue, bulk specimens of $\mathrm{LiAlO}_{2}$ material were exposed to liquid $\mathrm{Li}$ of normal purity at $500^{\circ} \mathrm{C}$; subsequently its electrical resistance was measured as a function of temperature up to $\square 700^{\circ} \mathrm{C}$ in an Ar environment. Figure 33 shows the variation in $\mathrm{R} \mathrm{x} \mathrm{A} \mathrm{as} \mathrm{a} \mathrm{function} \mathrm{of} \mathrm{temperature} \mathrm{for} \mathrm{the}$ 
bulk $\mathrm{LiAlO}_{2}$ specimen after exposure in an $\mathrm{Li}$ environment at $300^{\circ} \mathrm{C}$. The value for $\mathrm{R} \times \mathrm{A}$ is $>10^{7} \square \cdot \mathrm{cm}^{2}$ at temperatures up to $\square 150^{\circ} \mathrm{C}$ during the heating cycle and below $\square 250^{\circ} \mathrm{C}$ during the cooling cycle. However, the resistance decreases monotonically above $250^{\circ} \mathrm{C}$ and reaches $\square 100 \square \cdot \mathrm{cm}^{2}$ (the minimum needed for fusion applications) at $\mathrm{T}>500^{\circ} \mathrm{C}$. Figure 34 shows the variation in $\mathrm{R} \times \mathrm{A}$ as a function of exposure time obtained on bulk $\mathrm{LiAlO}_{2}$ specimen after $\mathrm{Li}$ exposure. The figure shows that the $\mathrm{R} \times \mathrm{A}$ values under isothermal conditions of 336 and $339^{\circ} \mathrm{C}$ are a few orders of magnitude higher than that needed for application. At the temperature of $538-539^{\circ} \mathrm{C}$, the $\mathrm{R} \times \mathrm{A}$ values differ by a factor of $\square 50$ between the heating and cooling cycles. The results also indicate that the stability of composition and structure of the material (both bulk phases and coatings) as a function of temperature can play a large role in the resistance values and that a multiple heating/cooling cycles may be needed to stabilize thermally stabilize the material, in addition to exposures in a Li environment.

Information presented in this report shows that the experimental approaches used in the present program can deliver coatings with adequate electrical resistance for application in Licooled fusion devices. Additional experiments and analysis of the coating procedures and coating/Li interactions are underway to examine in-situ development of coatings and long-term performance of these coatings in $\mathrm{Li}$ and under thermal cycling conditions.

\section{SUMMARY}

We have developed $\mathrm{CaO}$ coatings by a thermal/chemical vapor deposition process and by an in-situ approach in a liquid Li-Ca environment. Results showed that thick adherent coatings can be fabricated by thermal/chemical vapor deposition, especially if a double Ca treatment is applied. Coatings were also developed in-situ in an Li-Ca environment but the resulting coating thicknesses were much less than desired. Furthermore, the coating composition was nonuniform with significant presence of $\mathrm{V}$ in several locations on the coated surface. Extensive microstructural analysis of the coatings developed by the thermal/chemical process showed almost $100 \% \mathrm{CaO}$ over a coating thickness of $20-30 \mu \mathrm{m}$ and the electrical resistance, measured by two-probe method, of these coatings was at least two orders of magnitude higher than the minimum required for blanket application. Electrical resistance of in-situ-developed coatings was adequate at temperatures up to $\square 350^{\circ} \mathrm{C}$ but decreased substantially at higher temperatures. The results obtained in this study indicate that $\mathrm{CaO}$ is a viable coating for $\mathrm{V}$-Li advanced blanket but needs significant additional effort, especially from the standpoint of structure/composition relation to its electrical resistance. Furthermore, in-situ measurement of resistance in $\mathrm{Li}$ is required to simultaneously evaluate the coating integrity, its resistance, and Li compatibility. 


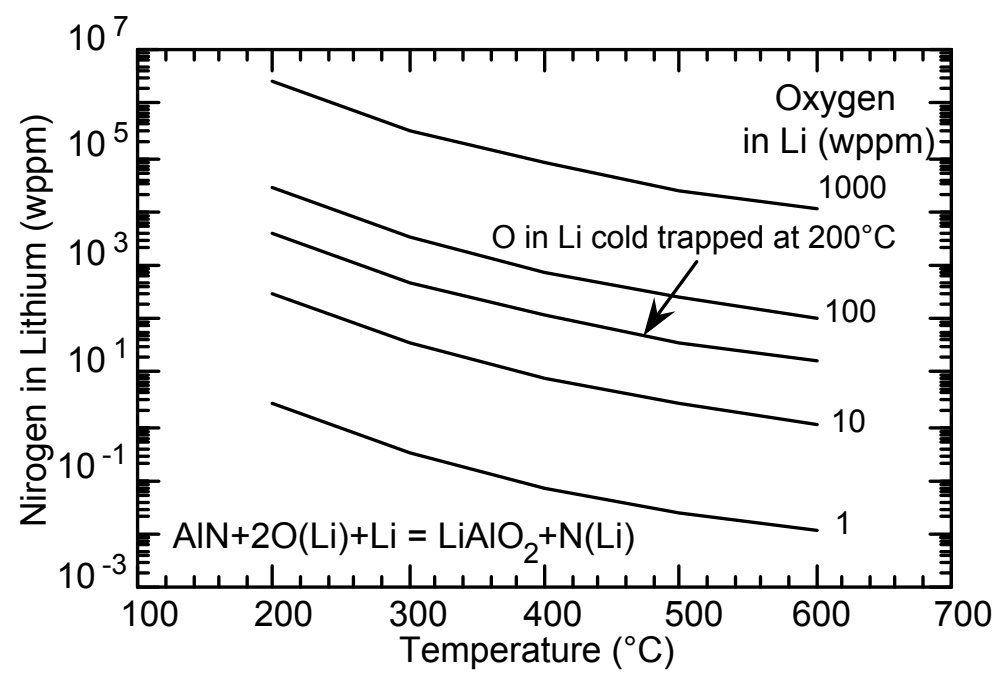

Fig. 32. Region of stability of $\mathrm{AlN}$ and $\mathrm{LiAlO}_{2}$ phases as a function of temperature and $\mathrm{O}$ and $\mathrm{N}$ concentrations in Li.

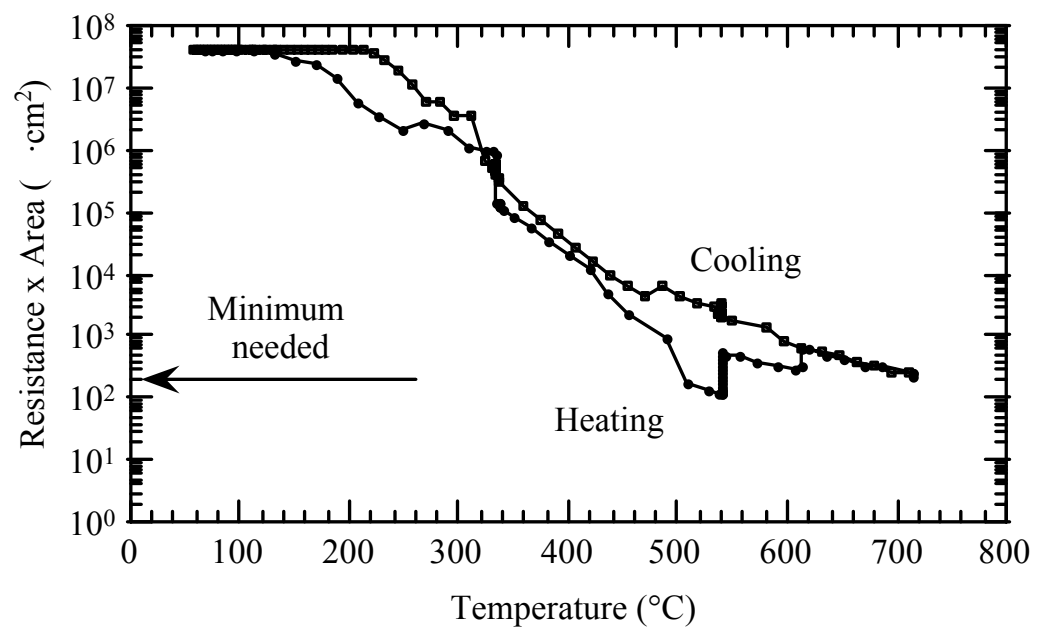

Fig. 33. Product of resistance times area as a function of temperature for bulk $\mathrm{LiAlO}_{2}$ after exposure in $\mathrm{Li}$ environment.

Detailed investigations were conducted on fabrication, metallurgical microstructure, compatibility in liquid Li, and electrical characteristics of AlN material produced by physical vapor deposition. Microstructural characterization of the coated samples was conducted by scanning electron microscopy, energy-dispersive X-ray analysis, and X-ray diffraction. Lithium compatibility studies were conducted in static systems by exposing AlN-coated specimens to $\mathrm{Li}$ over several time periods. Electrical resistance measured at up to $\square 700^{\circ} \mathrm{C}$ showed that the resistance values of the PVD coating of AlN were comparable to those of bulk AlN material. 


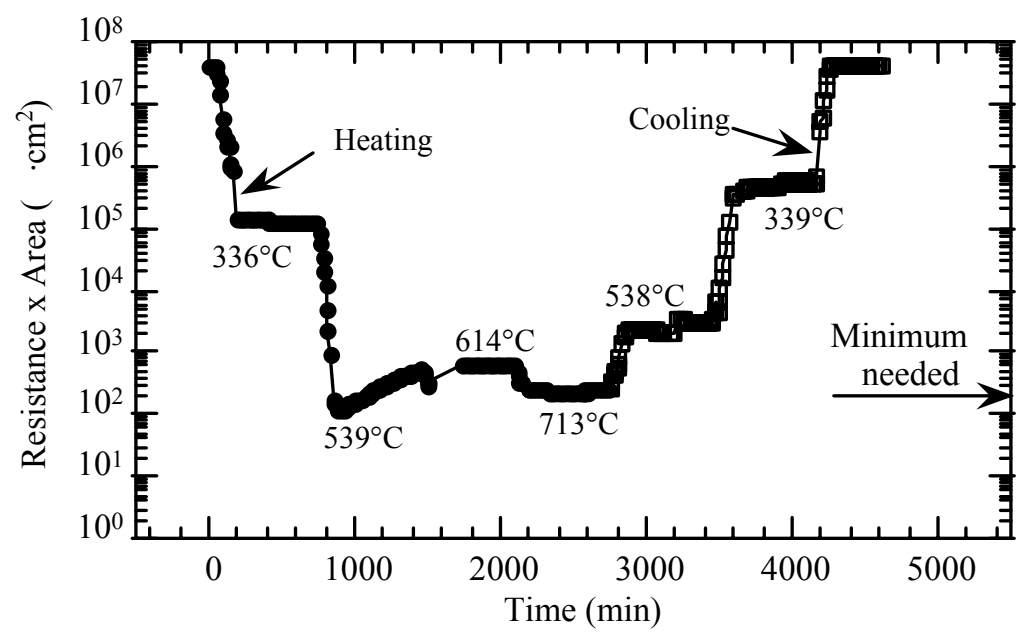

Fig. 34. Product of resistance times area as a function of time for bulk $\mathrm{LiAlO}_{2}$ after exposure in Li environment.

Furthermore, a comparison of the resistance values for the coated sample with that of a bulk $\mathrm{LiAlO}_{2}$ (possible reaction product between AlN and $\mathrm{O}$ in $\mathrm{Li}$ ) showed that the resistance will be adequate up to $\square 500^{\circ} \mathrm{C}$, even if all the AlN coating reacted to form $\mathrm{LiAlO}_{2}$; however, it is our conclusion that AIN as a coating can be stabilized in an $\mathrm{Li}$ environment by judicious control of the $\mathrm{O}$ and $\mathrm{N}$ concentrations in $\mathrm{Li}$.

\section{ACKNOWLEDGMENTS}

This work was supported by the U.S. Department of Energy, Office of Fusion Science, under Contract W-31-109-Eng-38. S. Wieder assisted with the construction of a test facility with computerized data acquisition for the resistance measurements on the bulk and coated specimens. R. C. Haglund assisted with the construction and operation of liquid metal test facilities; D. L. Rink assisted with the experimental program on exposure of specimens to liquid metal environments, resistance measurements on coated specimens, and microstructural analyses of the specimens; and B. Tani and P. Johnson assisted with X-ray diffraction analysis of specimens.

\section{REFERENCES}

1. K. Natesan, C. B. Reed, and R. F. Mattas, Fusion Engg. and Design, 27, p. 457, 1995.

2. S. Malang, H. U. Borgstedt, E. H. Farnum, K. Natesan, and I. V. Vitkovski, ibid.

3. S. Malang and L. Bühler, "MHD pressure drop in ducts with imperfectly insulating coatings," Argonne National Laboratory Report ANL/FPP/TM-269, 1994.

4. C. B. Reed, K. Natesan, T. Q. Hua, I. R. Kirillov, I. V. Vitkovski, and A. Anisimov, Fusion Engg. and Design, 27, p. 614, 1995. 
5. D. L. Smith and K. Natesan, Nucl. Technol. 22, p. 392, 1974.

6. K. Natesan, J. Nucl. Mater. 115, p. 251, 1983.

7. K. Natesan and D. L. Smith, Nucl. Technol. 22, p. 138, 1974.

8. K. Natesan, C. B. Reed, M. Uz, and D. L. Rink, "Development of Electrically Insulating CaO Coatings," Fusion Materials Progress Report for the Period Ending June 30, 1998, Argonne National Laboratory, DOE/ER-0313/24, p. 82, 1998.

9. K. Natesan, M. Uz, and S. Wieder, "Development of electrically insulating CaO coatings," Fusion Materials Semiannual Progress Report for Period Ending Dec. 31, 1998, Argonne National Laboratory, DOE/ER-0313/25, p. 69, 1999.

10. K. Natesan, M. Uz, and S. Wieder, "Development of electrically insulating CaO coatings," Fusion Materials Semiannual Progress Report for Period Ending June 30, 1999, Argonne National Laboratory, DOE/ER-0313/26, p. 57, 1999.

11. J. H. Park et al., Fusion Engg. and Design, 27, p. 683, 1995.

12. J. H. Park and T. F. Kassner, J. Nucl. Mater. 233-237, p. 476, 1996.

13. R. F. Mattas et al., Fusion Engg. and Design, 40, p. 659, 1998.

14. K. Natesan, "Development of Aluminum Nitride Insulator Coatings for Fusion Reactor Applications," Argonne National Laboratory Report ANL/FPP/TM-278 (1995).

15. K. Natesan, "Development of Aluminum Nitride Insulator Coatings for Fusion Reactor Applications," Argonne National Laboratory Report ANL/FPP/TM-290 (1996).

16. K. Natesan, C. B. Reed, D. L. Rink, and R. C. Haglund, J. Nucl. Mater., 258-263, p. 488, 1998. 


\section{Distribution for ANL}

$\underline{\text { Internal }}$

S. K. Bhattacharya

M. Billone

H. Drucker

Y. Gohar

A. Hassanien

C. A. Malefyt

R. Mattas

K. Natesan (10)

J.-H. Park

R. B. Poeppel

C. B. Reed

W. J. Shack

D. L. Smith

D. K. Sze

H. Tsai

M. Uz

Z. Zeng

FPP Files (10)

TIS Files

$\underline{\text { External }}$

ANL Libraries

ANL-E

ANL-W

Energy Technology Review Committee

H. K. Birnbaum, University of Illinois at Urbana-Champaign

I.-W. Chen, University of Pennsylvania

E. M. Logothetis, Ford Motor Co., Dearborn, MI

H. S. Rosenbaum, Fremont, CA

S. L. Sass, Cornell University

R. K. Shah, General Motors Corp., Lockport, NY

S. Smialowska, Ohio State University, Columbus 